\title{
WHERE ARE THE CHILDREN? DECONSTRUCTING THE ONTARIO AUTISM \\ PROGRAM
}

by

Abneet Kaur Atwal, Honours B.Sc., University of Toronto, 2016

\author{
An MRP \\ presented to Ryerson University \\ in partial fulfillment of the \\ requirements for the degree of \\ Master of Arts \\ in the Program of \\ Early Childhood Studies
}

Toronto, Ontario, Canada, 2017

C) Abneet Kaur Atwal 2017 


\section{AUTHOR'S DECLARATION FOR ELECTRONIC SUBMISSION OF A MRP}

I hereby declare that I am the sole author of this MRP. This is a true copy of the MRP, including any required final revisions.

I authorize Ryerson University to lend this MRP to other institutions or individuals for the purpose of scholarly research.

I further authorize Ryerson University to reproduce this MRP by photocopying or by other means, in total or in part, at the request of other institutions or individuals for the purpose of scholarly research.

I understand that my MRP may be made electronically available to the public. 


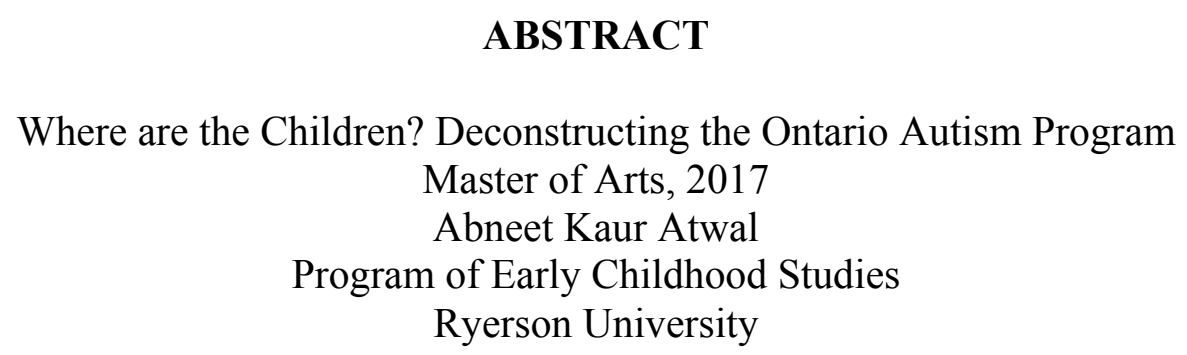

The Ontario Autism Program (OAP) provides behavioural supports and services to autistic children and youth, and their families. This study applied a critical discourse analysis (CDA) to examine the OAP policy documents using a children's rights framework. The purpose of the study was to examine how autistic children's rights are respected in the OAP policy documents. A CDA of the documents led to three key findings: the difference in roles of different social groups, quantifying and classifying autistic children, and the one size fits all approach in the program. The three themes present in the OAP policy documents are power and dominance, ideologies of childhood, and the medical model. The ways in which children are presented suggests that children's rights are being neglected. The paper concludes with recommendations for how clinicians can facilitate children's participation when implementing the program and changes required in the policy documents to incorporate a children's rights framework.

Keywords: autism, children's rights, development, medical model, policy, power 


\section{ACKNOWLEDGEMENTS}

I would like to thank my supervisors, Dr. Jason Nolan and Dr. Aurelia Di Santo. Thank you for your ongoing support and guidance with this paper and throughout the program. Your commitment and belief in me have been essential to completing this paper. I am grateful for the opportunity to work with and learn from the both of you.

To Dr. Rachel Berman, thank you for encouraging me to pursue this study. I appreciate your guidance and advice throughout the program.

I would like to thank my family. I would not have been able to get through this program without all your support and love. To my parents, thank you for always providing me with opportunities to pursue my goals.

I would like to thank my writing group, Nicola and Meredith, the two of you have encouraged me throughout this process and were always there for me when I needed to talk things through. This process would not have been the same without you. 


\section{DEDICATION}

I dedicate my MRP to Nachhatar Kaur Atwal and Gurbax Singh Atwal. Although you were not here for this journey, the love and joy you filled our home with will always be with me. Thank you for all the lessons you taught me and inspiring me to always strive for more. 


\section{TABLE OF CONTENTS}

Chapter 1: Introduction .................................................................................................................... 1

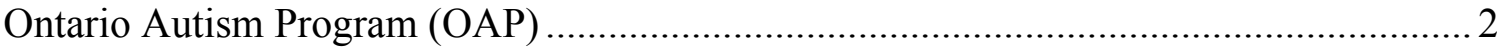

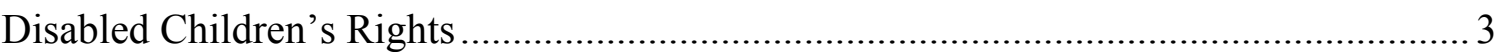

Researcher's Standpoint

Purpose and Significance of this Study ...................................................................... 5

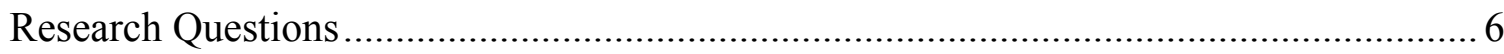

Chapter 2: Literature Review..................................................................................................................

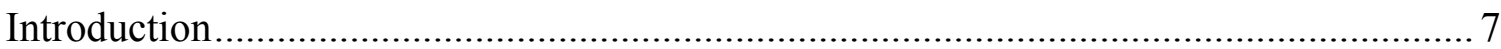

History of Behavioural Interventions...........................................................................

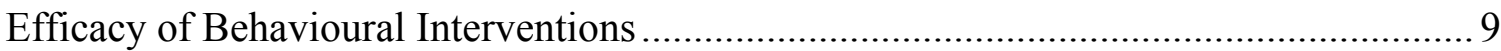

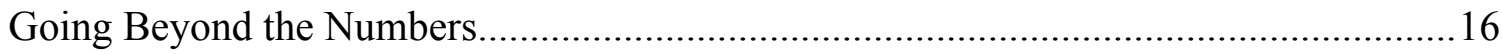

Behavioural Interventions and Children's Rights .........................................................18

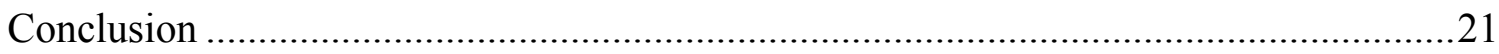

Chapter 3: Methodology...............................................................................................................22

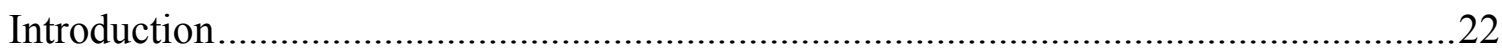

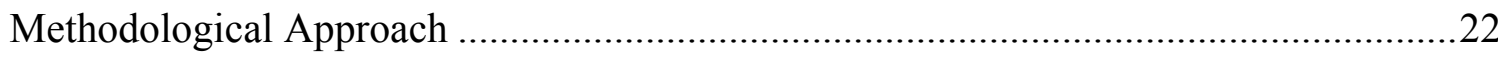

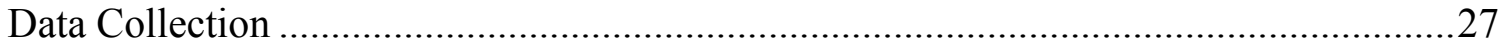

Approach to Data Analysis ...................................................................................28

Chapter 4: Findings ..................................................................................................................................31

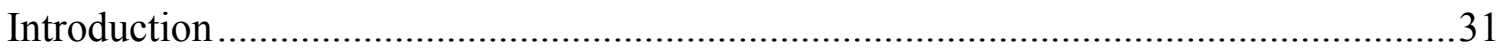

The Role of Children, Youth, Family, and Clinicians ....................................................32

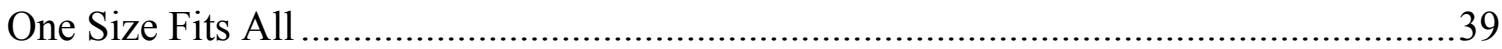


Quantifying and Classifying Autistic Children..........................................................42

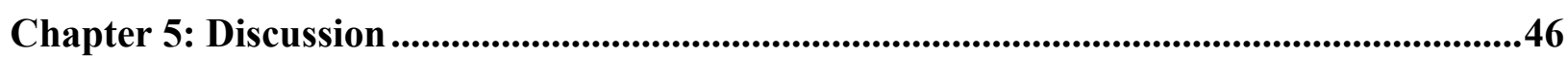

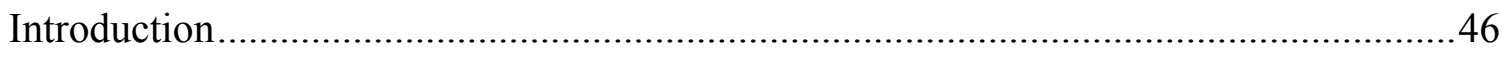

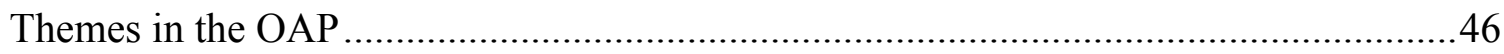

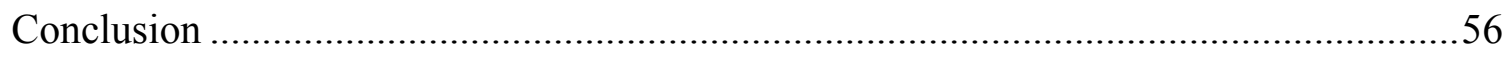

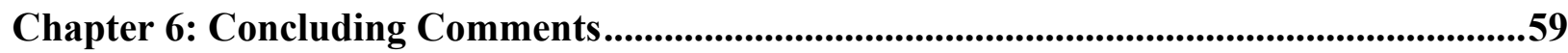

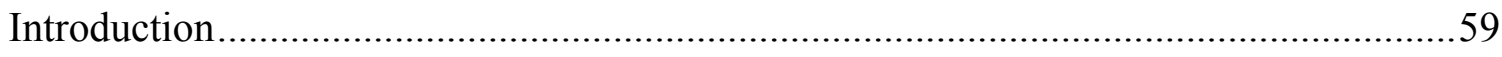

Recommendations and Future Research ...........................................................59

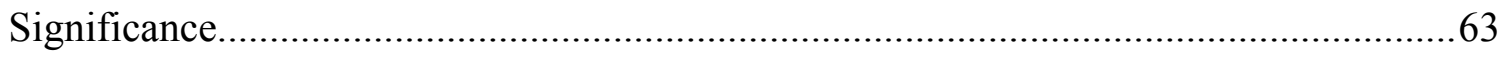

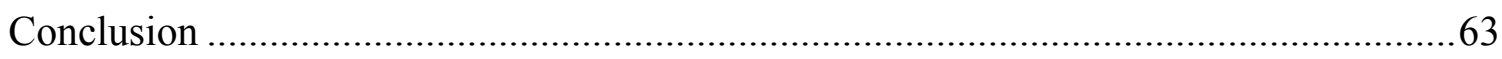

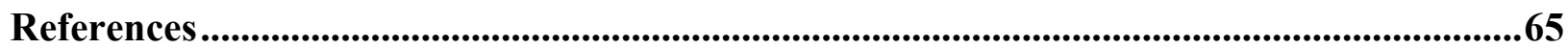




\section{LIST OF TABLES}

Table 1 - Descriptions of the Main Sections of the Four Documents Analyzed........................30

Table 2 - Summary and Comparisons of Key Findings for Role of Children, Youth, Families,

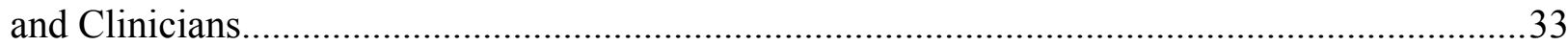

Table 3 - Summary and Comparison of Key Findings for One Size Fits All .........................40

Table 4 - Summary and Comparison of Key Findings for Quantifying and Classifying Autistic

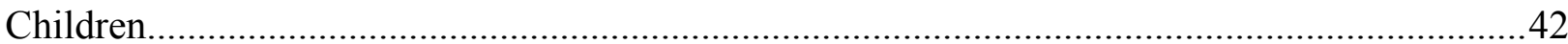




\section{LIST OF KEY TERMS}

ABA - Applied Behavioural Analysis

AIP - Autism Intervention Program

ASD - Autism Spectrum Disorder

CANS - Child and Adolescent Needs and Strengths

CARS - Childhood Autism Rating Scale

CDA - Critical Discourse Analysis

CDS - Critical Disability Studies

CEC - Clinical Expert Committee

CRPD - Convention on the Rights of People with Disabilities

IBI - Intensive Behavioural Intervention

MCYS - Ministry of Children and Youth Services

NRC - National Research Council

OAP - Ontario Autism Program

UNCRC - United Nations Convention on the Rights of Children

VABS - Vineland Adaptive Behaviour Scales 


\section{CHAPTER 1: INTRODUCTION}

Autism Spectrum Disorder (ASD) is defined as persistent deficits in social communication and interaction, and restricted, repetitive patterns of behaviour or activities (American Psychological Association, 2013). The Ontario Ministry of Children and Youth Services (MCYS; 2017a) defines ASD as, “a neurodevelopmental disorder with qualitative differences and impairments in reciprocal social interaction and social communication, combined with restricted interests and rigid and repetitive behaviours" (p. 8). The MCYS (2017c) estimates that there are approximately 40,000 autistic children and youth in Ontario. In 2012, the National Epidemiologic Database for the Study of Autism in Canada (NEDSAC) estimated that 1 in 94 children were diagnosed with ASD in Canada (Autism Ontario, 2017). The large numbers of children being diagnosed with ASD has led to long wait times for services and supports in Ontario (Gordon, 2012). Despite the large numbers of children being diagnosed with ASD, there is a lack of research on autistic children's rights (Glynne-Owen, 2010; Ladd, 2005).

In order for autistic children and youth to be to be eligible for and receive behavioural services and supports through the Ontario government, children must have a diagnosis accompanied by other assessment and observational data (MCYS, 2017a; MCYS, 2017b). The process of using assessments and observational data to determine intervention needs of children is based on a medical model approach (Ladd, 2005; Shyman, 2016). The medical model leads to the pathologization of autism (Glynne-Owen, 2010) and perpetuates the view that autistic individuals must be treated (Broderick \& Ne'eman, 2008; Shyman, 2016). The approaches being used for autism interventions such as applied behavioral analysis (ABA) and intensive behavior analysis (IBI) attempt to modify and change autistic children to fit within society (Glynne-Owen, 2010). The dominant ideologies of the medical model, which focus on labelling, categorizing, 
and deficits are reinforced through the use of multiple assessments and attempts made to change the individual through interventions. The process of comparing children to the 'normal' child, leads to the identification of areas where the child is not meeting the goals based on their age and stage in development. These are the deficits that begin to define children in the medical model, leading to attempts to 'normalize' them (Glynne-Owen, 2010).

Critical disability studies (CDS) proposes a social model of disability, which focuses on social and environmental barriers faced by disabled people (Watson, 2012). The individual with the disability is not seen as being the 'problem', instead society as a whole is seen as the 'problem' (Watson, 2012). Based on this definition, it can be argued that the way in which society is organized leads to the creation of disability. Attempting to change the individual and focus on their deficits, as the medical model does, puts the onus and responsibility on the individual to change. The view of disability as a disease, shifts the focus to finding a 'cure' (Broderick \& Ne'eman, 2008). Instead, the social model embraces differences and promotes the rights of all individuals. The use of a social model of disability in conjunction with a children's rights framework, would shift the discussion to promoting the rights of disabled children by focusing on the way society is constructed rather than the 'deficits' of disabled children.

\section{Ontario Autism Program (OAP)}

The Ontario Autism Program (OAP) consists of supports and services for children and youth diagnosed with ASD (MCYS, 2017b). Previously, the supports and services for autistic children and youth consisted of the Autism Intervention Program (AIP; MCYS, 2007) and ABAbased services and supports (MCYS, 2011). The goal of the AIP, was to provide "high quality, evidence-based intensive behavioural intervention (IBI) and associated services" (MCYS, 2007,

p. 4). Regional programs used assessments to determine eligibility, duration, and intensity of the 
intervention (MCYS, 2007). To provide more behavioral services for autistic children, the MCYS (2011) released further guidelines for ABA-based services for autistic children and youth. The addition of ABA-based services and supports increased access to government funded intervention. The goal was to provide services and supports on a short-term basis to focus on development areas identified as being the highest priority for children and youth (MCYS, 2011).

To streamline the program, the MCYS (2017c) introduced changes in the delivery of services and supports for autistic children and youth, and their families. This change is described as transforming the system, reducing wait times, and ensuring that all children and youth receive the services they require (MCYS, 2017c). The new OAP, is described as being more familycentered and service will be based on need (MCYS, 2017a). However, the new OAP will continue to provide behavioural supports and services. The program was introduced and rolled out across the province during the course of this study. As the new program is being implemented, it is important to examine the policy documents. One of the areas requiring further analysis is how the documents outlining the program respect children's rights.

\section{Disabled Children's Rights}

In 1990, Canada signed on to the United Nations Convention on the Rights of the Child (UNCRC) and subsequently ratified it in 1991 (Office of the High Commissioner for Human Rights (OHCHR), 1990). As of 2010, Canada also ratified the Convention on the Rights of Persons with Disabilities (CRPD; OHCHR, 2008). The UNCRC works in conjunction with the CRPD to promote the rights of disabled children. Both Conventions seek to ensure that disabled children are respected and not discriminated against. The UNCRC and CRPD promote the active participation of disabled children in matters affecting them and protect their fundamental freedoms. Article 2 of the UNCRC (OHCHR, 1990) states that all rights listed in the Convention 
are respected, while Article 1 of the CRPD (OHCHR, 2008) states that the purpose of the Convention is to protect the human rights and fundamental freedoms of all disabled people. According to the OHCHR (1990, 2008), disabled children's best interests must be a primary consideration in all actions which concern them and they also have the right to express themselves in matters concerning them (OHCHR, 1990; OHCHR, 2008). Despite the fact that disabled children's rights are acknowledged by both Conventions, there remains limited research on autistic children's rights with respect to the services and supports they receive (Glynne-Owen, 2010; Ladd, 2005). The present study will add to the limited research on autistic children's rights by examining the policy documents for the OAP, using a children's rights framework.

\section{Researcher's Standpoint}

Critical discourse analysis (CDA) acknowledges the inherent subjectivity of the analysis based on the researcher's perceptions and understandings of the text (Fairclough, 2003). Therefore, it is important to identify my position in relation to the research. My work with autistic children and their families, who are directly impacted by the OAP, has led me to conduct this research. The ongoing and recent changes to the OAP is one factor guiding this research. In 2016, the MCYS announced that there would be changes to the OAP, in order to decrease the number of children on waitlists for intervention. Following this announcement, concerns about funding and availability of programs were raised by families and advocates (Gordon, 2016a). Although the MCYS later backtracked (Gordon, 2016b), this announcement led me to question whether children's rights were being addressed and respected by the program.

As a graduate student and someone who works with children and families directly impacted by the OAP, I am in a privileged position through which I can critically examine the program and provide support and information to the families I work with. Many of the families I 
work with belong to minority cultures and/or are immigrants. I identify as belonging to a minority group and I am also a child of immigrants. My parents faced many difficulties navigating the education and healthcare system. Many of the families I work with report the same difficulties. My objective therefore, when working with autistic children and their families is to support them by providing information in order to help them make choices regarding services and to advocate on behalf of their child.

\section{Purpose and Significance of this Study}

The purpose of this study is to critically analyze the OAP using a children's rights framework in order to assess whether the OAP policy documents respect the rights of autistic children. The UNCRC and the CRPD will provide an alternative method for analyzing the program. Due to the ongoing discussion and newly introduced changes to the OAP (Gordon, 2016a; Gordon, 2016b; MCYS, 2017c), it is important to examine whether the new policy documents are addressing the needs of autistic children and their families.

Although the MCYS (2017c) has continued to promote the new OAP as changed and improved, it is important to examine how children's rights are addressed and respected by the program. The new OAP merges the AIP (MCYS, 2007) and ABA-based services and supports (MCYS, 2011) to form a more streamlined, uniform program (MCYS, 2017c). However, it continues to rely on behavioural services and supports, such as ABA and IBI. Therefore, it is important to examine whether behavioural supports and services acknowledge and respect autistic children's rights.

Finally, this research is important, as it builds upon the work and research exploring children's perceptions about issues affecting them. Although it is beyond the scope of this study to gain children's perceptions on their participation in the OAP, it may contribute to setting a 
foundation for doing so. It is important to discuss the role of autistic children's rights with respect to the services and supports they receive. These services and supports impact their daily lives and the lives of those they interact with.

\section{Research Questions}

Through a critical discourse analysis (CDA) based on the work of van Dijk $(1993 ; 1995)$ and Fairclough (1995), this study explored autistic children's rights within the Ontario Autism Program policy documents. The two overarching questions that guided this research are:

- How are children's rights acknowledged and respected in the Ontario Autism Program policy documents?

- Which areas of children's rights are ignored or underrepresented in the Ontario Autism Program policy documents?

As a consequence of the changes to the OAP (MCYS, 2017a; MCYS, 2017b), a sub-question for this study is: How has the new Ontario Autism Program (MCYS, 2017a; MCYS, 2017b) evolved from the Autism Intervention Program (MCYS, 2007) and Applied Behavioural Analysis based services and supports (MCYS, 2011) with respect to children's rights? 


\section{Chapter 2: Literature Review}

\section{Introduction}

In this section I will present a review of the literature on the use of behavioural interventions with autistic children and autistic children's rights. I will begin by outlining the emergence and history of behavioural interventions and then discuss more recent research on the efficacy of behavioural interventions such as IBI and ABA. Then, I will discuss research examining issues with the reporting of results in behavioural studies. I will end this section by discussing key areas of children's rights related to supports and services autistic children receive.

\section{History of Behavioural Interventions}

The use of methods and interventions to alter behavior dates back to the mid 1900s (Skinner, 1993/2014). Behavior theorist Skinner (1993/2014), describes how he used reinforcement to elicit responses from rats. The method of operant conditioning uses reinforcement and punishment to strengthen or extinguish particular behaviors (Skinner, 1974). Reinforcement is the consequence of a behaviour and it may be positive or negative (Skinner, 1974). Positive reinforcement strengthens any behavior which produces the reinforcer, while negative reinforcement strengthens any behavior which reduces it. Punishment, on the other hand, is used to remove a behavior or change the behavior that elicits the punishment (Skinner, 1974).

The techniques used by Skinner in his experiments with animals were eventually adapted to use with autistic children. Most notably, Lovaas adapted strategies such as reinforcement and punishment for young children diagnosed with autism (Lovaas, Schaeffer, \& Simmons, 1965; Lovaas, Koegel, Simmons, \& Long, 1973; Lovaas, 1987). In one of the earliest documented applications of these strategies with autistic children, the use of pain to modify autistic children's 
behavior was explored (Lovaas et al., 1965). Lovaas et al. (1965) used an "electrified grid on the floor" (p. 100) to induce shock when the children performed "pathological behaviors" (p. 100). Lovaas et al. (1965) described these behaviors as both self-stimulatory and tantrum behaviors. When one of the children exhibited either of these behaviors, experimenters urged the children to come to them. If the children did not follow through, they were shocked until they approached and sought the comfort of the experimenters (Lovaas et al., 1965). The purpose was for children to avoid the punishment and seek the comfort of an adult to stop the 'pathological behavior'. The two children participating in this study began to seek the comfort of the adult as soon as they exhibited the targeted behavior. This finding led the researchers to conclude that both social and affectionate behaviors increased as a result of using electric shock as punishment (Lovaas et al., 1965) However, with only two participants in this study, it is hard to generalize the results and conclude that the intervention will lead to the same results for all autistic children.

Between 1964-1973, Lovaas et al. (1973) conducted a follow-up study with 20 autistic children, to decrease self-stimulatory, self-destructive, and tantrum behaviors (Lovaas et al., 1973). The method used included: (1) reinforcement withdrawal, such as placing the child in isolation; (2) aversive punishment, such as a slap or electric shock; or (3) reinforcement of incompatible behavior (Lovaas et al., 1973). Children's responses were recorded along with scores on assessments. The authors reported that inappropriate behaviors were reduced and appropriate behaviors increased following intervention (Lovaas et al., 1973). However, they also noted the heterogeneity among the participants. The intervention was more effective for some children compared to others. Lovaas (1987) suggested that behavioral interventions could lead autistic children to reach 'normal' functioning. To maximize gains, Lovaas (1987) subjected autistic children to lengthy hours of intervention 
Observations and standardized assessments were the key tools used in the early studies on behavioral interventions for autistic children (Lovaas et al., 1965; Lovaas et al., 1973; Lovaas, 1987). The methods used included painful punishment such as slapping and electric shock (Lovaas et al., 1965; Lovaas et al., 1973). These methods were described in an interview of Lovaas by Paul Chance (1974). In this interview, Lovaas stated, "You have a person in the physical sense--they have hair, a nose and a mouth--but they are not people in the psychological sense" (Chance, 1974, p. 76). He continues, "You have the raw materials, but you have to build the person" (Chance, 1974, p. 76). Autistic children were not seen as being full humans on their

own. Instead, they were seen as needing to be fixed in order to become fully human. Research on IBI for autistic children today is heavily influenced by the early research conducted by Lovaas and his colleagues (Glynne-Owen, 2010). Glynne-Owen (2010) explains that current research continues to use standardized assessments and quantitative measures to assess autistic children and behavioral interventions. The methods and tools used in behavioural interventions, initiated by Lovaas, continue to be used today and are widely researched in studies examining efficacy of behavioural interventions for autistic children.

\section{Efficacy of Behavioural Interventions}

As discussed, IBI and ABA are the two key behavioral interventions being used. Both, based on the principles of applied behavioral analysis rely on the framework developed by Lovaas and his colleagues. ABA is the most widely used method of intervention for autistic children (Ladd, 2005; Shyman, 2016). The MCYS (2011) defines ABA as the scientific principles of learning and behavior used to build "useful repertoires and reduce problematic ones" (p. 22). IBI is the intensive application of ABA, in which children receive between 20-40 hours of intervention per week either in 1 on 1 or small group settings (MCYS, 2011). When 
measuring the efficacy of behavioral interventions for autistic children, the key area examined is the effect on developmental domains such as: cognition, language, and adaptive behaviors. Additionally, there is research on pre-intervention factors relating to children and intervention characteristics, and long-term outcomes of behavioural interventions.

Cognition. Measures of IQ are consistently used as indicators of cognition when measuring efficacy of autism intervention programs. In the early 1900s, Binet and Simon (1948) set out to create a measure of intelligence for children. To develop these scales, the tests were standardized by studying children in institutions and 'normal' children. The goal of these methods of testing is to measure natural intelligence rather than reading, writing, and other acquired knowledge. Different tools used to measure IQ include: Mullen Scales of Early Learning, Bayley Scales of Infant Development, Standford-Binet Intelligence Scale: Fourth Edition, and the Wechsler Preschool and Primary Scale of Intelligence (Freeman \& Perry, 2010). These tools are used in efficacy studies to measure changes in cognition following behavioural interventions.

Freeman and Perry (2010) examined the efficacy of the IBI program used at Toronto Preschool Autism Service. The researchers used different IQ tests depending on the age of the child. These tests included: Mullen Scales of Early Learning, Bayley Scales of Infant Development, Standford-Binet Intelligence Scale: Fourth Edition, and the Wechsler Preschool and Primary Scale of Intelligence (Freeman \& Perry, 2010). The findings suggested that at the end of the intervention, IQ scores had improved significantly. However, the researchers did not have a control or comparison group in this study. Therefore, it is not possible to attribute the improvement specifically to the intervention program. Instead, factors such as maturation or stimulation may have contributed to the observed changes. 
An increase in IQ is observed following IBI (Cohen, Amerine-Dickens, \& Smith 2006; Hayward, Eikeseth, Gale, \& Morgan, 2009; Remington et al., 2007) but there are contradictory results regarding whether IBI leads to greater gains compared to other programs. Hayward et al. (2009) reported that although children receiving IBI showed gains in IQ following intervention, children participating in a parent mediated intervention program showed similar gains. On the other hand, when IBI was compared to regular services from a local school, the group receiving IBI improved significantly more in their IQ (Cohen et al., 2006; Remington et al., 2007). The inconsistent results between studies further suggest that the heterogeneity among autistic children may impact the efficacy of the intervention and that IBI may not be a one size fits all solution.

Language. Two key areas of language measured in IBI efficacy studies are expressive and receptive language. When comparing children receiving IBI with those receiving other services, the results are inconsistent. It appears that both groups of children tend to improve in both expressive and receptive language, with neither group outperforming the other significantly (Cohen et al., 2006; Magiati, Charman, \& Howlin, 2007; Zachor \& Ben Itzchak, 2010). However, some studies report IBI leads to significantly greater improvements in language (Remington et al., 2007; Sambandam, Rangaswami, \& Thamizharsan, 2014), while some report other programs, such as pivotal response training (PRT) lead to greater improvements (Mohammadzaheri, Koegel, Rezaee, Majid, \& Rafiee, 2014). Although PRT uses the techniques of $\mathrm{ABA}$, it differs from IBI as it uses naturalistic environments such as the home, children have more choice over the interaction and stimulus, and natural activities (e.g., mealtime, getting dressed, story time) serve as the context for the interactions (Pierce \& Schreibman, 1995). The 
changes in language mirror the changes in cognition. There is inconsistency in the outcomes across studies, with some children improving more than others.

Adaptive behaviors. The tool used to measure adaptive behaviors is the Vineland Adaptive Behaviour Scales (VABS; Sparrow, Balla, \& Cicchetti, 1984) The VABS consists of semi-structured interviews with parents and teachers to measure: communication, daily living skills, socialization, and motor skills. The studies discussed in this section utilized the VABS as the key tool to measure changes in adaptive behaviors.

In a study analyzing the IBI program in Ontario, Perry et al. (2008) used the VABS to measure changes in adaptive behavior for 332 children between the age of 1.6 to 7 years old. Children who participated in the study received services for 4 to 47 months and for 20 to 40 hours every week. Children showed significant improvement in communication and socialization, but there was a decrease in daily living skills, and no change in motor skills (Perry et al., 2008). Although children who participated in this study received varying amounts of intervention and the age range of the children was large, the researchers did not report whether the duration of the intervention or age of the children moderated the effects of intervention.

When IBI is compared to other interventions, similar results on the VABS are reported. Sambandam et al. (2014) reported significant increases in socialization for the behavioral intervention group. The comparison group, on the other hand, did not demonstrate similar outcomes. However, when comparing IBI to one-on-one support from a special education teacher, Eikeseth, Klintwall, Jahr, and Karlsson (2012) reported that the IBI group significantly improved in all areas of the VABS while the comparison group did not. Results point to improvements in socialization and communication (Eikeseth et al., 2012; Perry et al., 2008; Sambandam et al., 2014) for children participating in IBI. The results in other areas such as daily 
living skills and motor skills are not as promising (Perry et al., 2008; Sambandam et al., 2014). There is a possibility that the intervention is more focused on improving socialization and communication, leading to greater improvements in these areas compared to daily living skills and motor skills.

Individual level factors. There is a wide range of heterogeneity among autistic children (Glynne-Owen, 2010; Lovaas et al., 1973), making it important to examine whether there are mediating factors influencing the efficacy of behavioral interventions. One of these factors is the severity of autism. The Autism Diagnosis Observation Schedule (ADOS; Lord, Rutter, DiLavore, \& Risi, 1999) and the Childhood Autism Rating Scale (CARS; Schopler, Reichler, \& Renner, 1988) are two tools used to classify children based on their severity of autism.

Using the ADOS, Zachor and Ben-Itzchak (2010) separated children into two groups: high severity and low severity. The purpose of this was to determine whether autism severity mediates the effects of intervention. The results indicated that children classified as lower severity performed better on assessments measuring language, communication, daily living skills, and socialization (Zachor \& Ben-Itzchak, 2010). Perry et al. (2008) classified children into three groups using the CARS: high functioning, intermediate functioning, and low functioning. The children classified as higher functioning demonstrated the greatest improvement in IQ and mental age (Perry et al., 2008). The intermediate functioning group only demonstrated improvements in communication, while the lower functioning group did not show any significant improvements (Perry et al., 2008). Both studies point to autism severity as a potential mediating factor in the efficacy of the intervention.

Children classified as higher functioning (lower severity) tend to have greater improvements following intervention compared to those classified as lower functioning (higher 
severity; Perry et al., 2008; Zachor \& Ben-Itzchak, 2010). If IBI is not universal for all children with a diagnosis, then should it be the only option available for autistic children? Behavioral interventions such as IBI may not be in the best interests of all autistic children. These studies do not go beyond the standardized assessments to examine the overall impact of the intervention on children.

As with autism severity measures, IQ at intake has been examined as a potential mediating factor in the efficacy of the intervention. Results point to the fact that children with a higher IQ at intake tend to perform better in the intervention compared to children with a lower IQ at intake (Ben-Itzchak \& Zachor, 2007; Magiati et al., 2007; Zachor, Ben-Itzchak, Rabinovich, \& Lahat, 2007). One area where the largest differences appear is language. Children with a higher IQ tend to have significantly greater improvements in language compared to children with a lower IQ (Ben-Itzchak \& Zachor, 2007; Zachor et al., 2007). These results demonstrate that behavioral interventions such as IBI and ABA may not be a one size fits all approach (Glynne-Owen, 2010). Variation in pre-intervention factors predicting outcomes of the intervention, provide further evidence that children respond differently to interventions and teaching styles. In this case, children with higher IQ and lower severity may be performing better in the intervention because of differences in developmental rate and trajectory. Further, the roles of maturation and stimulation are not addressed in the research. There is a possibility that children with a higher IQ and lower severity may show the same trends without the use of a very structured intervention. However, to investigate this, intervention would have to be withheld from some children, which raises an ethical concern because some children will not be provided with what is considered the most effective intervention (National Research Council (NRC), 2001). 
These results point to autism severity and IQ at intake as potential moderating factors in the efficacy of behavioral interventions such as IBI and ABA. However, there are other potential factors that may moderate the effects of the intervention. Researchers in this area do not tend to look at other individual level factors such as culture, family language, and time spent in other activities. Thus far, the heterogeneity between autistic children has focused on areas such as severity and IQ, but there are factors that extend to the family, which may be impacting the efficacy of the intervention. To gain a better understanding of the impact of these factors, further research is required. Ultimately, this brings us back to the question of whether behavioral interventions are universal or whether there should be other options available for children and their families.

Characteristics of the intervention. In 2001, the American National Research Council (NRC) released a report on interventions for autistic children. The purpose of the report is to provide guidelines and recommendations on effective interventions for autistic children. The report suggests that autistic children should be involved in an intervention program for a minimum of 25 hours a week, for 12 months a year (NRC, 2001). To justify the intensity of intervention, there must be data supporting the lengthy hours. However, there is a lack of research on how the duration of intervention sessions impacts children and whether the longer sessions are more beneficial in terms of outcomes.

One study looking at the duration of sessions reported that for younger children, fewer hours of intervention lead to similar outcomes compared to children between 5 and 7 years old participating in greater hours of intervention (Granpeesheh et al., 2009). However, for children over 7, regardless of duration of sessions, similar outcomes were observed (Granpeesheh et al., 2009). There is a large gap in research on behavioral interventions and the amount of time 
children spend in sessions daily. This leads to difficulty in concluding whether the recommendations made by the NRC (2001) are in fact best practices.

Long-term outcomes. When looking at the efficacy of behavioral interventions it is important to examine whether the effects are sustained following termination of the intervention and what the overall impact the intervention has on children's lives. Although most studies examine outcomes of intervention while the children are actively participating in the intervention, very few studies follow-up and examine the outcomes once children have transitioned out of the program. Following up with five children who had transitioned out of an IBI program, O'Connor and Healy (2010) found that improvements in areas such as daily living skills, stereotypy and anxiety were not sustained. However, challenging behaviors, which were reduced during the intervention, were not observed again at follow-up (O’Connor \& Healy, 2010). Eikeseth, Smith, Jahr, and Eldevik (2007) also reported that when they followed up with children who had previously been enrolled in ABA, they found that improvements in the VABS behavior scale were maintained. Researchers fail to look at outcomes outside of those measured by standardized assessments relating to children's' development. Researchers have not examined the overall impact of participation in the intervention. This includes children's well-being, health, and participation in activities outside of the intervention.

\section{Going Beyond the Numbers}

As described above, the results reported regarding the efficacy of IBI and other behavioral interventions appear to be questionable. The findings do not provide a clear-cut answer as to whether the intervention is efficacious or not. In this section I will discuss the importance of examining research on behavioural interventions in a more holistic manner. 
Looking at the findings and conclusions by the researchers may not provide all the information about the efficacy of the intervention.

Laws (2013) raises the point that there is an inclination to seek results that confirm our beliefs. If researchers go into their study expecting certain results and wanting to confirm their beliefs, there is a high chance of confirmation bias (Laws, 2013). There is also a tendency to attempt to replicate positive results (Laws, 2016a). When researchers find negative results, those that do not confirm that an intervention is successful, there is a lower chance of publication. By not publishing negative results, publication bias is created (Laws, 2013). The issue raised is whether the reader gets the full story regarding the research in a particular area.

Laws (2016a) and Smits, Lakens, Ritchie, and Laws (2014) focus on publication and confirmation bias with respect to cognitive behavioral therapy (CBT) for psychosis. What emerges from the research conducted by Laws (2016a) is that when unpublished studies are included, the effect size becomes non-significant. Further, Laws (2016b) and Smits et al. (2014) explain how studies on CBT for psychosis lack correct blinding of researchers and do not always report pre- and post-test means. Lack of correct blinding leads to an inflated effect size and lack of reporting of all information leads to difficulty in replication of studies. What begins to emerge is a strong bias in the publishing of studies regarding the efficacy of CBT for treating psychosis.

Much of the work conducted by Laws (2016a; 2016b) and Smits et al. (2014) is centered around the bias in studies conducted on CBT for psychosis and schizophrenia. However, the point raised through this research can apply to other areas such as behavioral interventions used with autistic children. As outlined, the outcomes and efficacy of the intervention are inconsistent. What begins to emerge is that the intervention is most successful for children who are classified as high functioning and as having a high IQ (Ben-Itzchak \& Zachor, 2007; Magiati et al., 2007; 
Perry et al., 2008; Zachor et al., 2007; Zachor \& Ben-Itzchak, 2010). Therefore, it is difficult to conclude whether IBI should be considered a best practice. It is also important to note that the NRC (2001) has similar concerns about research on interventions being used with autistic children. The main concerns listed are: studies lack randomized controlled groups for both ethical reasons and due to difficulties matching families and children; interventions that are compared to IBI usually do not have the same intensity or duration; studies lack demographic information about children and their families; and the lack of generalization and maintenance of effects (NRC, 2001). Despite these concerns, the Ontario government continues to rely on behavioural interventions and it is the only intervention currently available to children and their families (MCYS, 2017a; MCYS, 2017b).

\section{Behavioural Interventions and Children's Rights}

Despite there being a substantial amount of research on behavioural interventions for autistic children, the research neglects the role of children within the research process. The focus of research to date, has been to determine outcomes of the intervention based on quantitative measures (Glynne-Owen, 2010). There is a widespread belief that children and their abilities can be quantified. The goal of such a model is to attempt to modify children so that they can fit into society (Glynne-Owen, 2010). The individuality and voices of the children are neglected through this approach. IBI and ABA use a structured, standardized approach (Glynne-Owen, 2010; Shyman, 2016), which may limit time for unstructured play and interactions. This section outlines some of the key articles in the UNCRC (OHCHR, 1990) and CRPD (OHCHR, 2008) that relate to interventions and supports for autistic children and their family.

Children are active agents in their own lives, the lives of those around them, and in the society in which they live (James \& Prout, 1997). The marginalization of children, leaves them 
relatively powerless in relation to the structures around them (Mayall, 1998). This power imbalance is evident in the research on autism interventions. The research relies on data collected through standardized assessments regarding children's development. The researchers do not engage in the process of including children's voices in their research. Consequently, the therapist holds the power and children are expected to behave in a particular way in order to avoid punishment or get a reward (Shyman, 2016). Article 12 of the UNCRC (OHCHR, 1990) ensures children the right to express their views freely in matters affecting them. Article 12 states, "the views of the child being given due weight in accordance with the age and maturity of the child" (OHCHR, 1990, p. 4). Although a child's age is listed as a component in considering their views, maturity has the potential to go beyond age and traditional developmental views. Additionally, Article 7(3) of the CRPD (OHCHR, 2008) states that children with disabilities have the right to be "provided with disability and age appropriate assistance to realize this right" (p. 8). According to Article 21 of the CRPD (OHCHR, 2008) disabled individuals have the right to express themselves, which includes being involved in providing and receiving information. Based on these Articles, autistic children have the right to provide and receive information, and it is important for those working with them to facilitate this process.

Article 12 of the UNCRC (OHCHR, 1990) goes beyond giving children a voice. There are four elements that should be considered: space, voice, audience, and influence (Lundy, 2007). It is not enough just to ask children what their views are, but they must also be listened to and acted upon (Lundy, 2007). Article 12 works in conjunction with other articles such as Article 2 (non-discrimination), Article 3 (best interests), Article 19 (right to be safe), Article 13 (right to information), and Article 5 (right to guidance from adults). Children are not given the choice to opt out of the studies, nor is there any evidence suggesting that there is an attempt to seek assent 
from the children (Glynne-Owen, 2010; Shyman, 2016). At no point do children's views factor into how the intervention is implemented and whether the intervention is successful in terms of what the children and their family need and want.

Article 30 of the UNCRC, focuses on respecting culture, religion, and language for children belonging to a minority or indigenous culture (OHCHR, 1990). However, the use of standardized assessments and reliance on a Western view of development may be denying some children this right. Further, Article 29 states, "the education of the child shall be directed to: the development of respect for the child's family, his or her own cultural identity, language and values" (OHCHR, 1990, p. 9). The family system is an important component of children's lives and interventions must recognize them as being an essential component. Family-centered care is based on the belief that optimal development occurs when there is a supportive family and community environment (Rosenbaum, King, Law, King, \& Evans, 1998). Family-centered care respects Article 29 and 30 because one of the key premises is to respect the differences and uniqueness of families (Rosenbaum et al., 1998).

According to Zachor et al. (2007), one of the reasons for the 'success' of ABA is the use of structured teaching settings and predetermined learning goals. However, if the goal is for children to 'learn', structured interventions may not be the only way for this to occur. For example, there are many benefits to play that overlap with the goals of behavioural interventions. Play is meant to be a pleasurable and spontaneous activity, without extrinsic goals (Hirsh-Pasek \& Golinkoff, 2008). For the activity to be considered play, it should be child-centered, allowing children to explore problems and questions they are interested in (Kamii \& DeVries, 1993). Article 31 of the UNCRC states, "States Parties recognize the right of the child to rest and leisure, to engage in play and recreational activities appropriate to the age of the child and to 
participate freely in cultural life and the arts." (OHCHR, 1990, p. 9). This right is being denied when children are expected to participate in lengthy and structured intervention sessions daily. Time spent in the intervention takes away time from other activities and interactions, which the child may want to participate in. The amount of time spent in structured activities, including the intervention, consumes valuable time that can be spent in leisure and play activities.

\section{Conclusion}

The use of IBI and ABA as a technique to change the behavior of autistic children has been well documented. However, a thorough search of the literature, however, presents only one side of the story. Researchers have continued to use the same methods to test the efficacy of autism interventions. Standardized assessments only provide information about developmental outcomes. Research on supports and services for autistic children, does not examine them from the perspective of the children participating. For children to be seen as social actors in their own lives and the lives of those around them (James \& Prout, 1997), a children's rights framework would provide more insight as to whether the OAP respects the fundamental rights of children. The review of the literature outlined the historical roots of the interventions used with autistic children and how the intervention is being used and researched today. The purpose of this study is to contribute to the limited research on autistic children's rights with respect to the supports and services they receive, specifically through the OAP. 


\section{Chapter 3: Methodology}

\section{Introduction}

The purpose of this chapter is to outline the methodology used in this study. This study used a critical discourse analysis (CDA). I will begin by providing a framework to the methodological approach. The CDA used in this study is informed by Fairclough (1995) and van Dijk $(1993 ; 1995)$. In addition to the frameworks presented by van Dijk $(1993 ; 1995)$ and Fairclough (1995), the questions and tools presented by Gee (2014) guided the analysis of the documents.

\section{Methodological Approach}

By examining a particular issue or problem, CDA focuses on the relations of power, dominance, and inequality, and how these are reproduced through different discourses (van Dijk, 1995). CDA goes beyond simply observing and describing text and talk by examining what is absent in the text, the implicit content, how power is being exercised, and the historical conditions through which the text was produced (Fairclough, 1995). Fairclough (1995) explains that the implicit content of a text includes how the texts work in the society and culture within which the communication occurs; the textual form, structure, and organization of text; processes such as production, distribution, and consumption of text; and analysis of the practices at the level of the institution and discourse within which the text is embedded.

CDA acknowledges that there is an inherent subjectivity in the approach (Fairclough, 1995; van Dijk, 1995). Chouliaraki and Fairclough (1999) explain that CDA must be both reflexive and self-critical about its own position. This includes how the research is conducted, how objectives and outcomes of research are determined, and the relationships researchers have with the people whose lives they are analyzing. Critics of CDA point to the lack of objectivity 
with this approach (Breeze, 2011). Breeze (2011) explains that simply stating a standpoint does not give the researcher the freedom to interpret the data in a particular way for a specific purpose. CDA acknowledges this critique but also recognizes that the researcher's standpoint and position inform their research. The researcher is guided by a real issue or problem and they work in solidarity with those who are most impacted by it (van Dijk, 1993). Therefore, the subjectivity of the researcher is embedded within the analysis. In this study, the author explained her standpoint in the introduction of the paper to enhance trustworthiness. Another critique presented by Breeze (2011) is that analysis and interpretation of text must be well grounded with a theoretical foundation. Therefore, this study uses a children's rights framework alongside the sociology of childhood (James \& Prout, 1997; Mayall, 1998: Mayall, 2000) and critical disability studies (Broderick \& Ne'eman, 2008; Watson, 2012; Oliver, 1996) to ground the analysis and interpretation of the documents.

One of the key tenets of $\mathrm{CDA}$ is the role of power and dominance in relation to the specific issue or problem. Understanding the role of power and dominance is important in analyzing how the discourse contributes to its reproduction (van Dijk, 1993). Power in this context, goes beyond looking at the power an individual may possess, but instead focuses on the idea of relational power (van Dijk, 1993). Relational power is concerned with the relations between different social groups and how that power is exercised and circulates through a network (Foucault, 1980). One way for a social group to exercise this power is through text.

More specifically, CDA is concerned with the ways in which power is abused (van Dijk, 1993). This relates to the concept of dominance. Power and dominance are closely related as both tend to be "organized and institutionalized" (van Dijk, 1993, p. 255). As Mayall (1998) explains, children can be viewed as a marginalized group. In relation to the political and social 
structures around them, they are relatively powerless (Mayall, 1998). Due to the organization of society and the institutions which operate within society, children are seen as dependents. However, from the perspective of the sociology of childhood, children are not passive subjects (James \& Prout, 1997). The relational aspect of power involves the idea of control (van Dijk, 1993). With respect to children, their lives are heavily controlled by adults and their beliefs about childhood, limiting children's active participation in their daily lives (Mayall, 2000). Policies present one example of a text through which one social group may be attempting to exercise their power over another group. Mayall (2000) further argues that children's wishes and expressed needs must be considered in both policy and practice. There are currently power imbalances between the social groups involved in policy and practice, and those whom are affected by it. This power imbalance is exemplified in research with autistic children. The use of quantitative approaches prevents the voices of those being researched from being heard (GlynneOwen, 2010). One reason for this is the use of the medical model and the pathologization of disability.

Critical disability studies (CDS) seeks to challenge and explore how the use of binary categories has impacted the social relationships between people "with and without impairment" (Watson, 2012, p. 197). The pathologization of autistic children in research and the use of the medical model in early intervention has led to continuous attempts to 'normalize' autistic children (Glynne-Owen, 2010; Shyman, 2016). It is through the use of the medical model that autistic children are further marginalized. The medical model provides the power for one or more social groups to "dictate what is to be regarded as normal versus abnormal" (Shyman, 2016, p. 369). Ultimately creating a method to 'treat' or intervene. By labelling one group as 'normal' and the other as 'abnormal' a dominance hierarchy is created and reinforced by discourse. 
Funding by groups such as Autism Speaks is directed towards finding causes, prevention, treatments, and curing autism (Broderick \& Ne'eman, 2008). Broderick and Ne'eman (2008) explain that this process further perpetuates the idea that autism is a disease. By viewing autism as a disease, society and parents engage in a process of intervening (Broderick \& Ne'eman, 2008), to 'normalize' the autistic individual. A social model of disability focuses on changing the environment to make it more accessible and accommodating to the individual (Oliver, 1996). The contrasting discourses of the social and medical model become amplified with the intersectionality of childhood. CDS and the sociology of childhood can work together to address the intersectionality of childhood and disability in this study.

Although CDS and the sociology of childhood form the theoretical foundation for this study, these perspectives will be applied to a children's rights framework. The sociology of childhood and children's rights have many commonalities. According to James and Prout (1997), children should be viewed as capable and active participants in their daily lives and the lives of those around them. This directly relates to Article 12 of the UNCRC (OHCHR, 1990). Lundy (2007) explains that the right for children to freely express their views involves four components: space, voice, audience, and influence. For children to be actively involved in decision making, they should be provided with opportunities to express their views, supported to express their views, be listened to, and their views should be acted upon as appropriate (Lundy, 2007). By providing children with the opportunities to express themselves and children seeing adults act upon their views, children will feel more empowered. In order for children's rights to be respected, a shift is required in the view that children are 'incomplete' human beings (Liebel, 2012) as this view perpetuates the idea that children are dependent on adults. However, Leibel (2012) explains that children's rights provide a method to reduce the idea of children being 
dependent on adults and to strengthen their autonomy. Decisions in policy and practice concerning children tend to be dictated by adults (Mayall, 2000). By doing so, the dependence of children on adults is strengthened. If children were to be involved in this process using the four components described by Lundy (2007), children's rights could be respected in the area of policy and practice. To determine if children's rights are being respected, it is important to examine what steps are taken by adults to provide children with these opportunities.

One of the neglected areas concerning autistic children's rights is gaining their consent and assent to participate in research and policy (Glynne-Owen, 2010; Ladd, 2005). Within the body of literature concerning interventions for autistic children, researchers neglect to disclose whether assent was sought from the children participating in the study (Glynne-Owen, 2010). Autistic children are key participants in studies measuring the efficacy of behavioural interventions, yet they are not consulted at any point in the process and are treated as passive subjects without a voice. As well, the continued use of standardized assessment tools and the one size fits all approach to interventions neglects the individuality and diversity of the child (Glynne-Owen, 2010). Based on a children's rights framework, it is necessary for researchers to consider whether this is in the best interests of the child (Elwood \& Lundy, 2010). Article 3 of the UNCRC (OHCHR, 1990) states that in all decisions regarding children, their best interests should be the primary consideration. To fully respect this right, children should be provided with opportunities to actively participate in decisions concerning them. However, if they are treated as passive subjects in the assessment process, these rights will continue to be neglected. For children to be considered competent and active participants (James \& Prout, 1997), children's rights in policy and practice must be viewed in a holistic manner. 
The main objective of CDA is to analyze how power and dominance are reproduced in discourse (van Dijk, 1993). There are two ways in which this occurs. First, the dominant group may restrict the access or control over discourses to certain groups (van Dijk, 1993). Second, with having the power to control the access to discourse, the dominant group can indirectly influence the minds of others (van Dijk, 1993). It is important to examine what is happening within the text to reproduce power and dominance and how this is happening using a particular text. In the present study, the use of power and dominance was examined specifically with respect to autistic children's rights as articulated in the OAP policy documents.

A CDA framework was chosen for this study because the purpose of the study is to examine the ways in which autistic children are positioned within the OAP. This approach will allow for the examination of how power, dominance, and inequality are reproduced with respect to autistic children's rights within the OAP. Both the sociology of childhood and critical disability studies (CDS) are key concepts that make up the CDA approach used in this study. Together, these theories provide a framework for approaching an analysis of how autistic children's rights are represented in the OAP.

\section{Data Collection}

The documents used for this study were chosen through a thorough search of the MCYS OAP webpage. The documents include: Ontario Autism Program Clinical Framework (2017a), Ontario Autism Program Guidelines (2017b), Autism Intervention Program Guidelines (MCYS, 2007), and Applied Behaviour Analysis-Based Services and Supports Guidelines (MCYS, 2011). The Ontario Autism Program Clinical Framework (2017a) provides the guidelines for clinicians working with children, youth, and families, and provides information for families regarding how clinical decision making will occur. The Ontario Autism Program Guidelines (2017b) set out the 
guidelines and expectations for the implementation and delivery of the OAP across the province. Together, these documents form the core of the OAP. The Autism Intervention Program Guidelines (MCYS, 2007) and Applied Behaviour Analysis-Based Services and Supports Guidelines (MCYS, 2011) will be included in this analysis for two reasons. First, these two documents guided the implementation and delivery of interventions for autistic children prior to June 2017. Second, while the new OAP is in its initial phase, these documents will continue to be used in conjunction with the new guidelines (MCYS, 2017b). The four documents analyzed are available and accessible through the MCYS website. See Table 1 for descriptions of the key sections in each of these documents. For the purposes of this study, only documents specific to the OAP program were examined, and these documents provide the foundation for the OAP. There are other documents available through the MCYS that provide information about the program but do not represent the core of the program and the practices used within the program, and therefore were not included in the study.

\section{Approach to Data Analysis}

Once the documents were collected, they were coded and analyzed using the 28 tools outlined by Gee (2014) ${ }^{1}$. Grounding this process were the concepts of power, dominance, and inequality as outlined by van Dijk (1993; 1995), along with the frameworks presented in the methodological approach. Prior to coding the documents, the documents were read to get general information about their contents (Creswell, 2014). Following this, the data were hand coded and categorized. For this study, the researcher used pre-established language relating to CDA, children's rights, the sociology of childhood, and CDS to code the documents. Once the data

\footnotetext{
${ }^{1}$ See https://www.slideshare.net/abdullahktk2/james-paul-geehowtododiscourseanalysisatbookfiorg. For a description of the tools go to p. 27 of the website.
} 
were coded and categorized, findings were grouped into key themes. The 28 tools outlined by Gee (2014) guided the analysis process. Gee (2014) suggests analyzing the text starting with the fourth and final unit of tools because they relate to the larger concepts within the text. Through the coding process, the goal of the analysis was to respond to the 28 questions. Once all four documents were coded, a reliability check was run by directly answering the 28 questions starting from question twenty-eight and ending at question one.

To gain an understanding of how children's rights operate within the OAP, preestablished language based on children's rights was used to code the documents. I used language from the literature relating to children's rights (e.g., Glynne-Owen, 2010; Ladd, 2005; Lundy, 2007; OHCHR, 2005; OHCHR, 2013) to code and analyze the documents (i.e. autonomy, best interests, children's voice, diversity, empower, individuality, participation, and self-expression). Concepts presented by van Dijk (1993) were also used to code and analyze the documents (i.e. ideologies, access, reproduction of power and dominance, production, distribution, and consumption of text). Van Dijk (1993) defines ideologies as, "the fundamental social cognitions that reflect the basic aims, interests, and values of the group" (p. 258). Ideologies "organize and monitor the more specific social attitudes of social groups and their members" (van Dijk, 1993, p. 258). The ideas of power, dominance, and ideology build on children's rights, the sociology of childhood, and CDS. These three theoretical frameworks are related to the marginalization of particular groups and how power is exercised with respect to their role in society. The concepts presented by van Dijk (1993) along with the three frameworks, provided a more critical lens on the role of autistic children's rights in the OAP.

Three key findings emerged from the analysis: the role of different individuals and/or groups, one size fits all, and the process of quantifying and classifying autistic children. The 
codes were categorized under key themes: power and dominance, ideologies of childhood, and

the medical model.

Table 1

Descriptions of the Main Sections of the Four Documents Analyzed

\begin{tabular}{|c|c|c|c|c|}
\hline $\begin{array}{l}\text { Document } \\
\text { Section }\end{array}$ & $\begin{array}{l}\text { Autism } \\
\text { Intervention } \\
\text { Program (MCYS, } \\
\text { 2007) }\end{array}$ & $\begin{array}{l}\text { ABA-based } \\
\text { services and } \\
\text { supports (MCYS, } \\
\text { 2011) }\end{array}$ & $\begin{array}{l}\text { OAP Clinical } \\
\text { Framework (MCYS, } \\
\text { 2017a) }\end{array}$ & $\begin{array}{l}\text { OAP Guidelines } \\
\text { (MCYS, 2017b) }\end{array}$ \\
\hline Eligibility & - Severe end of ASD & - ASD diagnosis & - Not mentioned & - ASD diagnosis \\
\hline $\begin{array}{l}\text { Scope of } \\
\text { Services }\end{array}$ & $\begin{array}{l}\text { - Intensive } \\
\text { Behavioural } \\
\text { Intervention (IBI) } \\
\text { - } 20 \text { to } 40 \text { hours a } \\
\text { week } \\
\end{array}$ & $\begin{array}{l}\text { - } \text { ABA } \\
\text { - Short term, low } \\
\text { intensity }\end{array}$ & $\begin{array}{l}\text { - Continuum of } \\
\text { behavioural services } \\
\text { and supports }\end{array}$ & $\begin{array}{l}\text { - Continuum of } \\
\text { behavioural } \\
\text { services and } \\
\text { supports }\end{array}$ \\
\hline $\begin{array}{l}\text { Settings for } \\
\text { Services } \\
\end{array}$ & $\begin{array}{l}\text { - Centre and/or } \\
\text { home based }\end{array}$ & $\begin{array}{l}\text { - Variety of } \\
\text { settings }\end{array}$ & - Not mentioned & $\begin{array}{l}\text { - Variety of } \\
\text { settings }\end{array}$ \\
\hline Assessments & $\begin{array}{l}\text { - Childhood Autism } \\
\text { Rating Scale } \\
\text { (CARS) } \\
\text { - Vineland Adaptive } \\
\text { Behaviour Scales } \\
\text { (VABS) }\end{array}$ & $\begin{array}{l}\text { - Childhood } \\
\text { Autism Rating } \\
\text { Scale (CARS) } \\
\text { - Vineland } \\
\text { Adaptive } \\
\text { Behaviour Scales } \\
\text { (VABS) }\end{array}$ & $\begin{array}{l}\text { - Child and Adolescent } \\
\text { Strengths and Needs } \\
\text { (CANS) } \\
\text { - Formal } \\
\text { developmental, } \\
\text { functional, and } \\
\text { behavioural } \\
\text { assessments } \\
\end{array}$ & - Not mentioned \\
\hline $\begin{array}{l}\text { Types of } \\
\text { Service } \\
\text { Plans }\end{array}$ & $\begin{array}{l}\text { - Individual } \\
\text { Program Plan: } \\
\text { goals and structure } \\
\text { of intervention }\end{array}$ & $\begin{array}{l}\text { - ABA-based } \\
\text { service plan: } \\
\text { skills to be } \\
\text { taught, structure } \\
\text { of services, } \\
\text { outcomes }\end{array}$ & $\begin{array}{l}\text { - Behaviour Plan: } \\
\text { behaviours and } \\
\text { domains addressed, } \\
\text { intervention } \\
\text { approach, therapeutic } \\
\text { expectations }\end{array}$ & $\begin{array}{l}\text { - Family Service } \\
\text { Plan: family } \\
\text { story, people } \\
\text { involved in } \\
\text { services, } \\
\text { parent/caregiver } \\
\text { services } \\
\end{array}$ \\
\hline $\begin{array}{l}\text { Key } \\
\text { Domains }\end{array}$ & - Not mentioned & $\begin{array}{l}\text { - } \text { Behaviour } \\
\text { management and } \\
\text { emotional } \\
\text { regulation } \\
\text { - Communication } \\
\text { - Social skills } \\
\text { - Daily living } \\
\text { skills }\end{array}$ & $\begin{array}{l}\text { - Social and } \\
\text { interpersonal } \\
\text { - Communication } \\
\text { - Cognitive function } \\
\text { - School readiness } \\
\text { - Motor } \\
\text { - Adaptive skills } \\
\text { - Play and leisure } \\
\text { - Self-regulation } \\
\text { - Vocational } \\
\text { - Challenging } \\
\text { Behaviour }\end{array}$ & $\begin{array}{l}\text { - Social and } \\
\text { interpersonal } \\
\text { - Communication } \\
\text { - Cognitive } \\
\text { function } \\
\text { - School readiness } \\
\text { - Motor } \\
\text { - Adaptive skills } \\
\text { - Play and leisure } \\
\text { - Self-regulation } \\
\text { - Vocational } \\
\text { - Challenging } \\
\text { Behaviour }\end{array}$ \\
\hline $\begin{array}{l}\text { Monitoring } \\
\text { and } \\
\text { Evaluation }\end{array}$ & $\begin{array}{l}\text { - Regional programs } \\
\text { accountable }\end{array}$ & $\begin{array}{l}\text { Outcomes, } \\
\text { parent/caregiver } \\
\text { satisfaction }\end{array}$ & - Not mentioned & $\begin{array}{l}\text { - Outcomes, } \\
\text { parent/caregiver } \\
\text { and youth } \\
\text { satisfaction }\end{array}$ \\
\hline
\end{tabular}




\section{Chapter 4: Findings}

\section{Introduction}

The OAP provides behavioural services and supports to autistic children and youth, and their families. In June 2017, the MCYS implemented the new OAP and published two new policy documents, the Ontario Autism Program Clinical Framework (MCYS, 2017a) and Ontario Autism Program Guidelines (MCYS, 2017b). The clinical framework (MCYS, 2017a) outlines how clinicians will work with families and helps families understand how clinical decisions are made. The guidelines (MCYS, 2017b) set out the expectations for the delivery of the OAP. The previous policy documents for autism services included the Autism Intervention Program Guidelines (MCYS, 2007) and Applied Behaviour Analysis-Based Services and Supports Guidelines (MCYS, 2011). See Table 1 for descriptions of the key sections of each of these four documents. In this section I will present the findings that emerged from my CDA of these documents. The three major findings are the role of different individuals/groups, one size fits all, and the process of quantifying and classifying autistic children.

The roles of different individuals and groups are made distinct across all four documents. For a summary and comparison of the roles of different groups in the four documents, see Table 2. Children and youth are mentioned alongside one another in most areas of the documents, but there are instances when they are not. This impacts the way in which their participation is described in the documents. The role of the family is also clearly articulated in the documents. Clinicians constitute the group with the most active role in the OAP documents. Clinicians are actively involved at every stage, from the development of the documents to the transition of 
youth out of the program. I will present my analysis of these four groups (children, youth, families, and clinicians), pointing out similarities and differences in the four documents.

The one size fits all approach continues to be used in the new OAP and is highlighted in all four documents. The documents list different options for delivering supports and services, but the options are limited to only behavioural interventions. Flexibility with service delivery may occur with respect to the settings, duration, and intensity of the intervention, however, this is determined by the assessments conducted by clinicians. The one size fits all approach to services and supports assumes that all autistic children will benefit from the same intervention. Table 3 provides a summary of the key findings in relation to this approach and provides a comparison of the old and new documents.

The focus of the methods described in the four documents is to quantify and classify autistic children. See Table 4 for a summary of how autistic children are quantified and classified in the old and new documents. The OAP is founded on medical and developmental psychology models. The reliance on these models focuses activities on 'treatment' of autistic children to accelerate their development, increase functional skills, and reduce challenging behaviours. Data collected from assessments and observations will contribute to the development of the behaviour plan. The behaviour plan will outline the goals determined by the family and clinician, and track progress and changes in children and youth during their involvement in the program.

\section{The Role of Children, Youth, Family, and Clinicians}

The roles of different individuals and groups are described in all four documents. Although there is some overlap between the roles of members of different groups, there were some distinctions made between them and the power they hold. The MCYS (2017a; 2017b) does not define children and youth, but they are discussed as two distinct groups. This distinction 
factors in on their role in the OAP, as youth are provided with more opportunities to be active participants compared to children. The new program is described as family-centered, and this provides the family with more opportunities to be involved in planning and implementation. Clinicians are the are key players in all areas of the documents. Table 2 presents the key findings in relation to the roles of different individuals and groups in the OAP policy documents.

Table 2

Summary and Comparison of Key Findings for Role of Children, Youth, Families, and Clinicians

\begin{tabular}{|c|c|c|}
\hline $\begin{array}{l}\text { Key } \\
\text { Findings }\end{array}$ & $\begin{array}{l}\text { Autism Intervention Program } \\
\text { (MCYS, 2007) and ABA-based } \\
\text { services and supports (MCYS, 2011) }\end{array}$ & $\begin{array}{l}\text { OAP Clinical Framework (MCYS, 2017a) } \\
\text { and Guidelines (MCYS, 2017b) }\end{array}$ \\
\hline Children & $\begin{array}{l}\text { - Provided with behavioural supports } \\
\text { and services. } \\
\text { - Not involved in the planning and } \\
\text { decision-making process. }\end{array}$ & $\begin{array}{l}\text { - Shift to a child-centered approach. } \\
\text { - Passive recipients of behavioural supports } \\
\text { and services. } \\
\text { - Strengths considered in the planning of the } \\
\text { intervention. }\end{array}$ \\
\hline Youth & $\begin{array}{l}\text { - Provided with behavioural supports } \\
\text { and services } \\
\text { - Not involved in the planning and } \\
\text { decision-making process. }\end{array}$ & $\begin{array}{l}\text { - Considered stakeholders and have a role in } \\
\text { planning. } \\
\text { - Role is limited by the use of quantitative } \\
\text { data in determining goals. }\end{array}$ \\
\hline Family & $\begin{array}{l}\text { Parents and caregivers work with } \\
\text { the professionals to plan and make } \\
\text { decisions }\end{array}$ & $\begin{array}{l}\text { - Parents and caregivers work alongside the } \\
\text { clinicians in a family-centered approach. } \\
\text { - More inclusive of differences among } \\
\text { families e.g., culture and language }\end{array}$ \\
\hline Clinicians & $\begin{array}{l}\text { - Behavioural therapists are the main } \\
\text { group of professionals working } \\
\text { with the family, children, and } \\
\text { youth. }\end{array}$ & $\begin{array}{l}\text { - A family support team will work alongside } \\
\text { the family and/or youth. } \\
\text { - A family support worker will be assigned } \\
\text { to each family to coordinate services. } \\
\text { - Clinicians on the team are the experts in } \\
\text { behavioural interventions and treatment. }\end{array}$ \\
\hline
\end{tabular}

Role of children and youth. The new program is described as child, youth, and familycentered (MCYS, 2017a; MCYS, 2017b). There is a distinction made between child and youth but they are not defined (MCYS, 2017a; MCYS, 2017b). In some areas of the new documents, children and youth are listed together, whereas in other areas, children are not mentioned alongside youth. Youth have a more active role with respect to decision making and planning. 
Their input on the plan for how the intervention will occur is sought, while the same is not done with children. The view that youth are experts but children are not makes the distinction in their roles clear. Autistic children's and youth's role in the services and supports they receive through the OAP is important to assess because they are the key participants within the program. The findings with respect to the role of autistic children and youth in the program relates to them having a voice, being treated as passive objects, and the individualization of the intervention.

The guiding principles of the new OAP view children and youth as partners who actively engage in the intervention (MCYS, 2017a; MCYS, 2017b). One aspect of children and youth having a voice is through the assent and consent process. The clinical framework mentions seeking consent from children and youth when developing their behaviour plan. The document states, "the OAP Behavioural Clinician must document any necessary parental consent and, as appropriate, child/youth consent, to proceed with the plan" (MCYS, 2017a, p. 20). However, when the documents provide details about the different processes in the program, consent from family and youth is mentioned, but assent from children is not. For example, earlier in the same section, the document states, "the OAP Behavioural Clinician will explain the Behaviour Plan to the family/youth, and will document both the plan and parental/youth consent to proceed with the plan" (MCYS, 2017a, p. 20). There are sections in the documents when youth are also left out of the consent process. For example, when discussing the role of the behaviour clinician, only parental consent is discussed regarding treatment planning (MCYS, 2017a).

The differences in active participation between children and youth is not limited to the assent/consent process. Youth are listed as stakeholders alongside families and were consulted with prior to the development of the new OAP (MCYS, 2017a). Data on goals the youth achieved and the supports they believed would benefit others were collected from the focus 
groups (MCYS, 2017a). Children are not listed as stakeholders, nor did they participate in any focus groups. The OAP guidelines (MCYS, 2017b) include a section on monitoring and evaluation of the program and the document states that information will be collected regarding "parent/caregiver and youth satisfaction with service delivery" (p. 27). Children's satisfaction does not factor in. These findings demonstrate that there is a difference in the roles children and youth have within the OAP.

The description of the role youth will have in the new OAP compared to children, leads to differences in how these groups are perceived. The distinction is made in the clinical framework as it states that youth can expect "to be recognized as the experts in their own lives" (MCYS, 2017a, p. 12). The same is not said about children. When discussing building trust with clinicians, youth are mentioned and children are left out (MCYS, 2017a). By neglecting children in these two areas, children become the objects of the intervention rather than active, contributing participants. There are instances in which children and youth are not seen as partners. For example, when discussing the family service plan, the guidelines state that the plans, "reflect the shifting priorities of the family, the child's developmental stage, progress towards goals and objectives and transition planning" (MCYS, 2017b, p. 21). Children's and youth's priorities, needs, and interests are not mentioned as being included in the family service plan.

The individuality of children and youth does not play a large role in planning and decision making. One consideration for creating the behaviour plan are children's strengths and needs (MCYS, 2017a). However, the other factors include goals, and developmental and life stage (MCYS, 2017a). The guidelines do not describe the extent of involvement children and youth will have in determining strengths, needs, and goals. By building a trusting relationship 
with children and youth, clinicians could gather information about these areas rather than relying on data from assessments. The ambiguity in describing how the behaviour plan will be created, limits the potential for the involvement of children and youth in this process. Further, when describing the behavioural services provided, the guidelines (MCYS, 2017b) state, "services will be delivered in a manner that emphasizes and prioritizes the development, maintenance and generalization of functional skills, including those skills that prepare children and youth to more fully benefit from inclusion in typical settings" (p. 24). The description about how services will be delivered further emphasizes expectations of children and youth, without accounting for their individuality. Their role is being limited to being objects who are being intervened upon.

Role of family. The MCYS (2017a) defines family as, "parents, caregivers, grandparents, siblings and other relatives" (p. 8). Previously, in the MCYS (2011) guidelines for ABA-based services and supports, parent and caregiver were used instead of family. The change in terminology acknowledges the roles and participation of the entire family system, rather than just parents and caregivers. The role of the family is highlighted in the clinical framework (MCYS, 2017a) and the program guidelines (MCYS, 2017b). The key areas addressed are familycentered care, families as the experts, and responding to the needs of families from different cultures.

The clinical framework (MCYS, 2017a) emphasizes family-centered care directly in the introduction. In the new program, collaboration with the family is fundamental in decision making, planning, and delivering services and supports (MCYS, 2017a; MCYS, 2017b). When describing the roles of different members of the team, the document states, "emphasis on familycentered care creates a fundamental basis for service delivery" (MCYS, 2017a, p. 11).

Previously, the AIP (2007) addressed family involvement in terms of requiring parental consent, 
reviewing the program plan, and consultation to make clinical decisions. However, the AIP is not described as being family-centered. The new OAP focuses on family engagement, which involves "a sense of trust with the clinicians entrusted to work with them" (MCYS, 2017a, p. 11).

The new documents place an emphasis on building trust with the family and engaging them in the supports and services provided. When discussing family engagement, the clinical framework states, "this approach values parents and caregivers as experts on their child and as key decision makers in their child's interventions" (MCYS, 2017a, p. 11). By labelling the family as an expert on their child, the MCYS (2017a; 2017b) is respecting the voice and active participation of the family throughout their involvement with the program. However, children's voices are still being neglected in this process. By building trusting relationships with children, clinicians can learn more about them and have more opportunities to support them. As stakeholders, families were invited to participate in focus groups for the development of the new program (MCYS, 2017a). The topics of the focus groups were "the best ways to get to know their children, how to decide what to work on, and optimal communication with the clinical team" (MCYS, 2017a, p. 30). In addition to the focus groups, parents, clinicians, and teachers were asked to complete an online survey. Another method to increase family engagement is through the inclusion of family culture and language in the program.

In the new OAP, the MCYS (2017a; 2017b) acknowledges differences in culture and language. Both the AIP (MCYS, 2007) and ABA-based services and supports (MCYS, 2011) did not address differences in family culture and language as important components of service. The new guidelines state, "services are responsive to cultural, social, geographical and economic diversity and language needs of children, youth and their families" (MCYS, 2017b, p. 9). The clinical framework (MCYS, 2017a) also states that the assessments used will be culturally 
responsive and respectful. However, they do not provide examples of the steps they will take to ensure that assessments and other processes in the program are culturally responsive and respectful.

Role of clinicians. Under the new OAP, children and youth and families will have a team of professionals working with them. The clinical staffing requirements will remain the same as the AIP (MCYS, 2007) and ABA-based services and supports (MCYS, 2011) during the first phase of the new OAP (MCYS, 2017b). Along with the family, clinicians are considered experts within the OAP. The role of the clinicians is evident in the makeup of the clinical expert committee and clinician focus groups, their role in planning the services and supports, and the implementation of the OAP as a whole.

The ASD clinical expert committee (CEC) formed by the MCYS consists of a wide range of professionals including psychologists, board certified behaviour analysts, and speechlanguage pathologists (MCYS, 2017a). The goal of forming this committee was to gain information about "effective intervention, current research, and best clinical practices for working with children and young people with ASD" (MCYS, 2017a, p. 28). Autistic children and young people are not considered the experts and were not included on the CEC. The list of members does not explicitly state whether autistic adults were consulted with during this process. As stakeholders, clinicians were also consulted with through focus groups and surveys. The surveys helped identify the areas which have formed how services and supports will be planned and implemented (MCYS, 2017a). Although the family is considered an expert, clinicians had a larger role in the development of the new program.

Not only were clinician's fundamental in the development of the new OAP, they are also key players in working with autistic children and youth and their families. The clinical 
framework (MCYS, 2017a) states that parents can expect, "that clinicians will bring to their conversations their expertise and experience" (p. 12). The document continues by clearly outlining the role of the behaviour clinicians. They are described as "an expert in assessment and behavioural treatment options" (MCYS, 2017a, p. 13). In comparison to the role of children, youth and families, the role of clinicians is explained in greater depth and more clearly. However, the expectations also note that clinicians should work collaboratively with family, youth, and other professionals.

Collaboration between the clinicians, OAP family team, family, and youth is demonstrated in some areas of the OAP. Once a family support worker gathers information about the child or youth and family, the behaviour clinician develops the family service plan (MCYS, 2017a). Following the creation of the family service plan, the behavioural clinician will conduct assessments and observations to create the behaviour plan. One component of this process is “open discussion of the family's/youth's highest areas of need” (MCYS, 2017a, p. 18). Although youth are included in this discussion, the document then states that the plan is, "developed in collaboration with the family" (MCYS, 2017a, p. 18). The clinician remains a consistent figure in the steps to developing the behaviour plan but youth's involvement is not carried out throughout the steps. This is one example of clinicians having greater responsibility in service planning compared to other groups.

\section{One Size Fits All}

The types of services and supports provided through the new OAP, although described as individualized, remain restricted in scope. Table 3 provides a summary of the supports and services provided, structure of the program, and choices available to children, youth, and families. The new OAP follows the previous program in providing strictly behavioural services 
to autistic children and youth and their families (MCYS, 2017b). The documents describe the reasoning for providing behavioural services and supports, the structuring of the program, and how families will have choice.

\section{Table 3}

Summary and Comparison of Key Findings for One Size Fits All

\begin{tabular}{|c|c|c|}
\hline $\begin{array}{l}\text { Key } \\
\text { Findings }\end{array}$ & $\begin{array}{l}\text { Autism Intervention Program } \\
\text { (MCYS, 2007) and ABA-based } \\
\text { services and supports (MCYS, 2011) }\end{array}$ & $\begin{array}{l}\text { OAP Clinical Framework (MCYS, 2017a) } \\
\text { and Guidelines (MCYS, 2017b) }\end{array}$ \\
\hline $\begin{array}{l}\text { Supports } \\
\text { and } \\
\text { Services } \\
\text { Provided }\end{array}$ & $\begin{array}{l}\text { - IBI provided to children who are } \\
\text { considered lower functioning. } \\
\text { - ABA-based services and supports } \\
\text { available for those ineligible to } \\
\text { receive IBI. }\end{array}$ & $\begin{array}{l}\text { - Continuum of behavioural supports and } \\
\text { services available to children, youth, and } \\
\text { families }\end{array}$ \\
\hline $\begin{array}{l}\text { Structure } \\
\text { of } \\
\text { Program }\end{array}$ & $\begin{array}{l}\text { - Limited flexibility and } \\
\text { individualization of services and } \\
\text { supports. }\end{array}$ & $\begin{array}{l}\text { - More flexibility in the delivery of the } \\
\text { program. } \\
\text { - Depending on the needs of the child or } \\
\text { youth and family, more structured and less } \\
\text { flexible approaches may be required. }\end{array}$ \\
\hline $\begin{array}{l}\text { Choices } \\
\text { Provided }\end{array}$ & $\begin{array}{l}\text { - Only behavioural supports and } \\
\text { services available. }\end{array}$ & $\begin{array}{l}\text { - Only behavioural supports and services } \\
\text { available. }\end{array}$ \\
\hline
\end{tabular}

There are changes around the language used for the new OAP regarding interventions. Previously, the AIP (MCYS, 2007) outlined how IBI will be delivered and the ABA-based services and supports (MCYS, 2011) included other behavioural supports and services for autistic children and youth. In the new OAP, ABA and behavioural interventions are the terms used to describe the interventions provided to autistic children and youth. Although the term IBI is no longer used, children and youth are still eligible to receive the same intensity of intervention (MCYS, 2017a; MCYS, 2017b). The new OAP "will deliver a continuum of evidence based behavioural services" (MCYS, 2017b, p. 15). The program will use an evidence based approach to meet the needs of children, youth, and families. The services will be provided on a continuum ranging from more structured, adult-led intervention to less structured, child-led 
interactions. The program is presented as being flexible, with a range of services, offered in various formats and settings (MCYS, 2017b). However, the program is also described as addressing behavioural needs and the only option presented to families will be behavioural services (MCYS, 2017a; MCYS, 2017b). When options and choice are mentioned, they are presented as being for families, not children and youth. The flexibility appears to come through when discussing individualization of the program.

The structure of the program is presented clearly in some respects, but is more ambiguous in others. The way in which the structure of the program is presented differs from how it was previously presented. The AIP (MCYS, 2007) clearly outlined IBI services autistic children would receive. Whereas the current program provides a larger continuum of behavioural services and examples of different options are listed, they are not described in detail (MCYS, 2017a). Examples of some of the choices include: one-to-one, small group and/or peer mediated intervention (MCYS, 2017b). The family's preference is one of the many factors which will help determine the duration, approach, setting, and intensity of the intervention (MCYS, 2017b). The child's/youth's preference is not listed as one of these factors. The choice then is put in the hands of the family and clinicians, by leaving children and youth out of the discussion.

Although presented as a change in the new OAP, the direct funded option existed under the AIP (MCYS, 2007). The AIP (MCYS, 2007) states, "all Regional Programs must offer families the option of funding to purchase intensive behavioural intervention services privately" (p. 18). Autistic children who qualified for IBI, were supposed to be provided with the direct funded option. Furthermore, whether the family chooses the direct funded option or the regional program, children and youth will still be receiving the same behavioural services and supports 
(MCYS, 2017b). The choice provided to families is who the service provider is, not which types of services and supports they will receive.

\section{Quantifying and Classifying Autistic Children}

The new OAP is described as providing services based on need (MCYS, 2017b). This is also one of the features which will be focused on during the first phase of the new OAP. There are some subtle differences in how 'need' was determined in the AIP (MCYS, 2007) and ABAbased services and supports (MCYS, 2011) and how it is defined in the new OAP. However, the fundamental methods used are still based on the medical model and developmental theories. Assessments are used to measure strengths and needs, and develop goals for the intervention. The goal of this process is the support children and youth to achieve predetermined outcomes and reach "their full potential" (MCYS, 2017b, p. 4). See table 4 for a summary of how autistic children are quantified and classified.

\section{Table 4}

\section{Summary and Comparison of Key Findings for Quantifying and Classifying Autistic} Children

\begin{tabular}{|l|l|l|}
\hline Key & $\begin{array}{l}\text { Autism Intervention Program } \\
\text { (MCYS, 2007) and ABA-based } \\
\text { services and supports (MCYS, } \\
\text { 2011) }\end{array}$ & $\begin{array}{l}\text { OAP Clinical Framework (MCYS, 2017a) and } \\
\text { Guidelines (MCYS, 2017b) }\end{array}$ \\
\hline Quantifying & $\begin{array}{l}\text { - Focus on key developmental } \\
\text { domains: language, } \\
\text { cognition, and adaptive } \\
\text { behaviours }\end{array}$ & $\begin{array}{l}\text { - Services and supports will be provided based } \\
\text { on individual needs of families, children, and } \\
\text { youth. } \\
\text { - Quantitative tools are the key method in } \\
\text { determining the results of the intervention. }\end{array}$ \\
\hline Classifying & $\begin{array}{l}\text { - Use age and severity to } \\
\text { determine access to services } \\
\text { and supports. }\end{array}$ & $\begin{array}{l}\text { - The ages and stages model is used to } \\
\text { determine goals and outcomes } \\
\text { Expectations of children and youth are based } \\
\text { on a developmental model. }\end{array}$ \\
\hline
\end{tabular}

One of the system outcomes determined by the OAP Advisory Committee is to provide services and supports to children, youth, and families "within a timeframe that provides maximum therapeutic benefits" (MCYS, 2017b, p. 8). The goal of achieving therapeutic benefits is 
widespread in the clinical framework (MCYS, 2017a) and guidelines (MCYS, 2017b). A component of the behaviour plan is listing the "therapeutic expectations including anticipated risks and benefits" (MCYS, 2017a, p. 20). The idea of 'treatment' is present in parents' expectations of the program, the role of the behavioural clinician, development of the behaviour plan, delivery of the program, and monitoring and evaluating the program (MCYS, 2017a). For example, the role of the behaviour clinician is described as, "apply and recommend relevant and indicated treatments" (MCYS, 2017a, p. 13) and they will also assess "treatment fidelity" (p. 22). The OAP guidelines (MCYS, 2017) list the domains of needs that will be addressed through the program. Many of these are based on developmental areas such as communication, cognitive functions, school readiness, motor skills, adaptive skills, and interpersonal/social skills (MCYS, 2017b). The list of domains of need also contains play and leisure. The document states that "many individuals with ASD lack effective play and leisure skills, including deficits in conventional engagement with play items/activities, engagement in cooperative or imaginative play, and interest in, and friendships, with peers" (MCYS, 2017b, p. 17). The description of play and leisure provided by the MCYS (2017b) suggests that there is a right and wrong way for children to play, and that autistic children must be taught how to play in the right way.

The goal of 'treatment' is related to the developmental stages of children and youth. A factor influencing the family service plan is the "child's developmental stage" (MCYS, 2017b, p. 21). Furthermore, the behavioural services used will "support early child development to increase the rate of learning in young children in all areas of their development" (MCYS, 2017b, p, 25). The ages and stages model is exemplified by the methods used to determine goals for autistic children and youth. The new OAP has changed from the previous programs as children's age and severity of autism will not be the primary factors determining the services children receive 
(MCYS, 2017b). The AIP (MCYS, 2007) and ABA-based services and supports (MCYS, 2011) clearly stated that these factors influenced decision making. Although the new program states that these factors will not be used to determine eligibility, children and youth will still undergo assessments to determine the duration, intensity, and type of services and supports they will receive.

Assessments to determine the services and supports autistic children, youth, and their families will receive were used in the former program and will continue to be used in the new program. The AIP (MCYS, 2007), clearly stated that the VABS (Sparrow et al., 1984) and CARS (Schopler et al., 1988) would be used to determine eligibility and the types of services provided. The only assessment clearly mentioned in the clinical guidelines is the Child and Adolescent Needs and Strengths (CANS) (MCYS, 2017a). The CANS will allow for the collection of data to determine a baseline for children and youth and to keep consistency across the province to compare child and family outcomes across the province (MCYS, 2017a). Testing and assessing autistic children and youth is mentioned without always specifying which assessments will be conducted. For example, once the behavioural clinician has determined "behavioural challenges" (MCYS, 2017a, p. 18) they will conduct formal developmental, functional, and/or behavioural assessments as needed. The data from these assessments will inform 'treatment' decisions. The new OAP also states that assessments will be culturally responsive and respectful (MCYS, 2017a). However, the steps to achieve this are not outlined, nor are the specific assessments listed. When changes in children and youth occur or goals are met, updated assessments may be required to determine the next set of goals (MCYS, 2017a).

The goal of using the assessments is to track changes in children and youth and develop goals and priorities. As these change, further assessments are conducted and it becomes a 
cyclical process. When describing the approach to service delivery, the MCYS (2017b) states that it is outcome oriented. A systematic method is used "for selecting goals and strategies based on data-based assessment, monitoring progress and problem solving" (MCYS, 2017b, p. 16). Based on the assessments conducted, goals and priority areas are determined by clinicians and the family children and youth. The focus is on teaching particular skills and reducing particular behaviours (MCYS, 2017a; MCYS, 2017b). The family and clinician will set a timeframe to "achieve mastery" (MCYS, 2017a, p. 20) of the particular behaviour or skill. The cyclical process of assessing, setting goals, mastering skills, and reassessing is an ongoing process until the youth transitions out of the program. 


\section{Chapter 5: Discussion}

\section{Introduction}

The purpose of this CDA is to examine how the OAP policy documents support children's rights. This study is guided by a children's rights framework, the sociology of childhood and CDS. The theoretical frameworks allowed for an examination of autistic children's rights within the OAP. The three major themes in the OAP include: power and dominance, ideologies of childhood, and the medical model. The findings demonstrate that children's rights continue to be ignored in the OAP documents.

\section{Themes in the OAP}

Power and dominance. One of the themes in the OAP is the way in which power and dominance are exercised. More specifically, this discourse within the OAP centers around the limited power autistic children and youth hold, and the dominance of the 'experts' within the OAP. The way in which power is exercised in the development, planning, and implementation of the OAP leads to a clear distinction between different groups of people.

The power imbalance between different groups is exemplified from the earliest stages of the development of the new OAP. The ASD clinical expert committee (CEC) formed by the MCYS consisted of a range of professionals (MCYS, 2017a). Autistic adults, youth, and children were not provided with a role in the CEC. The power that the professionals hold allowed them to make decisions regarding autistic children and youth. Article 12 of the UNCRC (OHCHR, 1990) and Article 7 of the CRPD (OHCHR, 2008) state that disabled children should be involved in decision making, however this right was denied to them in the formulation of the OAP. This power imbalance trickled down to the stakeholder consultations. Although youth are listed as stakeholders (MCYS, 2017a), autistic children were once again left out. Parents, professionals, 
and autistic youth participated in focus groups and surveys (MCYS, 2017a). The topics of the focus groups for the professionals were more centered around decision making about planning and implementing the new OAP. As Mayall (2000) explains, decisions about policies regarding children tend to be made by adults, deeming children as dependent. The professionals and to some extent parents and caregivers, were provided with more power with respect to the discussions of their focus groups and the consequences of the discussions that occurred. Adults were provided with more power in the creation and development of the new OAP. Fairclough (1995) links power to having control and access to discourse. Children were denied control or access during the development phases. This differential in roles between adults and children, and non-autistics and autistics, demonstrates the marginalization of these groups in the development of the OAP.

According to Article 12 of the UNCRC (OHCHR, 1990), children have the right to express their views and to have those views heard. Lundy (2007) explains how Article 12 is not fulfilled without also respecting their right to information (Article 13), non-discrimination (Article 2), best interests (Article 3), and guidance from adults (Article 5). However, in the documents, children are being denied these rights. It is important to note that this right is respected for youth in some cases but not consistently. The new OAP suggests that youth can expect "to be recognized as the experts in their own lives" (MCYS, 2017a, p. 12). Although this builds on the previous program, in which youth were not labelled as experts, a distinction is being made between the competency and participation of children and youth based on age. And youth being labelled as experts still does not grant them the same level of participation as family and clinicians. For example, when the topic of determining goals and creating plans is discussed, youth are not always mentioned (MCYS, 2017a; MCYS, 2017b). Foucault (1980) describes 
relational power as being centered on the relations between social groups and how power circulates within those groups. A hierarchy forms with clinicians involved in every aspect of the development, planning, and implementation of the OAP (MCYS, 2017a; MCYS, 2017b). As stakeholders, family members also actively participate in many parts of the OAP. They are involved in making decisions about the services and are considered experts on their children (MCYS, 2017a). Youth are listed as experts but the family holds more power due to their greater role in planning and decision making. At the bottom of this hierarchy are children. Children are participants in the intervention but are not provided with the space to contribute in other areas of the OAP. For Article 12 to be fully respected, the OAP must recognize them as active participants and in order to fulfill this, they must have the opportunity to express their views, be facilitated in expressing their views must be listened to, and their views must be acted upon as appropriate (Lundy, 2007). Access and control continues to be provided to the adults involved, and limited to the youth and children participating in the supports and services.

The new OAP is presented as being flexible and providing choice to children and youth and their families (MCYS, 2017a; MCYS, 2017b). It is important to acknowledge that there is more flexibility in the new program compared to the previous one. One of the areas in which this flexibility is demonstrated is in the attempts to be more culturally inclusive. The MCYS (2017b) described services as being "responsive to cultural, social, geographical and economic diversity and language needs of children, youth and their families" (p. 9). The shift to a program which is more inclusive of different cultures follows through with providing family-centered care (Rosenbaum et al., 1998) and respects Article 29 and Article 30 of the UNCRC (OHCHR, 1990). However, these claims are made in the document without providing any information about how the MCYS will follow through with this. Research on behavioural interventions such as ABA 
and IBI (see Cohen et al., 2006; Eikeseth et al., 2012; Freeman \& Perry, 2010; Hayward et al., 2009; Magiati et al., 2007; Mohammadzaheri et al., 2014; Remington et al., 2007; Sambandam et al., 2014; Zachor \& Ben Itzchak, 2010) neglect analyzing the role of culture, language, and other family factors on the efficacy of the intervention. The foundation of the policy is behavioural interventions, but the interventions do not respect Article 29 or Article 30 of the UNCRC (OHCHR, 1990). Behavioural interventions may not be in the best interests of all children and youth and their families, and this is where the choice provided in the new OAP remains restricted in scope. The new OAP "will deliver a continuum of evidence based behavioural services" (MCYS, 2017b, p. 15) and the services will be delivered by an expert in behavioural interventions (MCYS, 2017a). The MCYS and the experts who are providing the services continue to have the control over which services are available and accessible for autistic children and youth in Ontario. There is potential for more flexibility in the new program because a continuum of services will be provided, however the theoretical foundation of the intervention remains the same as those used by Skinner $(1974 ; 1993 / 2014)$ and Lovaas et al. $(1965 ; 1973)$.

Laws' $(2013$; 2016a; 2016b) research on the use of CBT for individuals with schizophrenia demonstrates that efficacy studies do not always present all the information. The MCYS (2017a; 2017b) states that the interventions provided are evidence based, however research on the efficacy of behavioural interventions is not conclusive. Studies on the efficacy of behavioural interventions suggests that certain groups of autistic children, such as those classified as higher functioning, show greater improvements following intervention compared to those classified as lower functioning (for example see Ben-Itzchak \& Zachor, 2007; Magiati et al., 2007; Perry et al., 2008; Zachor, Ben-Itzchak et al., 2007; Zachor \& Ben-Itzchak, 2010). Based on this data, it is difficult to conclude that behavioural interventions are in the best 
interests of all autistic children, but this is not reported by the MCYS (2017a; 2017b). According to Article 13 of the UNCRC (OHCHR, 1990) children have a right to information, but this right is being denied by not neglecting to mention the gaps in the research. The research conducted by Laws (2013; 2016a; 2016b) and Smits et al. (2014) also suggests that publishing bias in psychological research impacts the results reported in studies. The issue of power and dominance arises when looking at which information is reported and provided to children and their families, and who is providing information to them. Children's right to information (Article 13) and right to guidance from adults (Article 5) is being denied by neglecting to report the gaps in research.

Due to the scope of the OAP, children and youth and their families, are restricted in the services they can receive (Ladd, 2005). To present the program as having more choice, the MCYS (2017b) states that the new program will have a direct funding option. Families can opt to receive services from a private provider and receive compensation from the MCYS. However, this is not a new addition to the program because it was also supposed to be available under the AIP (MCYS, 2007). Individuals working with the MCYS are in a position through which they can use their power to control the information presented to the general public. Furthermore, this option will continue to limit the choice in type of intervention because only particular professionals and providers qualify as appropriate. When there is contradicting data on the efficacy of behavioural interventions (see Cohen et al., 2006; Eikeseth et al., 2012; Freeman \& Perry, 2010; Hayward et al., 2009; Magiati et al., 2007; Mohammadzaheri et al., 2014; Remington et al., 2007; Sambandam et al., 2014 Zachor \& Ben Itzchak, 2010) and there is the potential that all the data is not presented in a truthful way, the question which arises is whether behavioural interventions are in the best interests of all autistic children and youth. Those with 
power can control the services and supports available, leaving children and youth and families with one option through the OAP.

Ideologies of childhood. The OAP documents make distinctions between different social groups: professionals, family, youth, and children. Children and to some extent youth, are powerless compared to the adults. This power differential reflects the ideologies adults have about children and youth. The social attitudes of adults regarding autistic children and youth are evident in their participation in the consent/assent process and the one size fits all approach.

The new OAP has made some adjustments in the consent/assent process from the previous program, however the new program still falls short by not including children in this process. The process of seeking consent includes youth alongside family in most instances (MCYS, 2017a; MCYS, 2017b). Seeking consent from children is only mentioned once when discussing moving forward with the behaviour plan (MCYS, 2017a). While the OAP defines family and the professionals in the program, children and youth are not defined, yet there remains a distinction between the two. Age is being used as the determining factor in deciding who is competent and capable to provide consent. However, every child is different, and age should not be the only factor considered when making this decision. Literature examining children's rights in interventions for autistic children report similar findings (Glynne-Owen, 2010; Ladd, 2005; Shyman, 2016). Glynne-Owen (2010) reports that efficacy studies neglect to report whether assent was sought from the children participating in the study. This further perpetuates the idea of children as dependents (Leibel, 2012; Mayall, 2000) and as 'incomplete' humans (Leibel, 2012). Respecting children's rights would provide a method to decrease this dependence and increase children's autonomy (Leibel, 2012). As active participants in the OAP, children should be involved in the assent/consent process. Clinicians can facilitate this process 
by providing information to children in an appropriate method and using both verbal and nonverbal cues to determine whether the child is providing assent to participate. Visual aids and augmented communication devices may also be used to facilitate children's participation. The social attitudes adults hold about children are exemplified in the consent/assent process. Their attitudes about the capabilities and competency of children has led to children being left out of a fundamental process in the OAP.

Adults' views about children's development and the reliance on behavioural methods for interventions for autistic children, perpetuates the one size fits all approach (Glynne-Owen, 2016). Behavioural interventions promote the idea that autistic children need to be changed for them to fit into society (Glynne-Owen, 2016). The new OAP continues to use behavioural supports and services as the foundation of the program. Although individuality of children and youth is acknowledged in the documents (MCYS, 2017a; MCYS, 2017b), the methods used do not acknowledge that diversity or individuality (Glynne-Owen, 2016). The one size fits all approach does not consider the heterogeneity among autistic children. Furthermore, attitudes that come to light through the OAP reflect the ages and stages model and normative development. Goals and outcomes are determined based on the age and stage of the child (MCYS, 2017a; MCYS, 2017b). Instead of focusing on the individuality of the child, the focus is on ensuring goals are met based on their stage in development.

The new OAP attempts to be more inclusive of culture and family diversity, yet developmental models are based on Westernized views about childhood. This view is also evident when examining the research on the efficacy of behavioural interventions. Standardized assessments are used to measure children's development in various domains such as cognition, language, and adaptive behaviours (see Cohen et al., 2006; Eikeseth et al., 2012; Freeman \& 
Perry, 2010; Hayward et al., 2009; Magiati et al., 2007; Mohammadzaheri et al., 2014;

Remington et al., 2007; Sambandam et al., 2014; Zachor \& Ben Itzchak, 2010). Even if the new OAP claims to be culturally responsive, the interventions being used are based on research which is not culturally inclusive. Intervention approaches being used reflect Western beliefs and ideas of normalcy (Welterlin \& LaRue, 2007). Not all cultures rely on a linear developmental trajectory, and this is not accounted for in research on autism interventions (Welterlin \& LaRue, 2007). According to Article 29 and Article 30 of the UNCRC (OHCHR, 1990), children have the right to their culture, language, and identity. By working within a restricted system, this right is not respected. Furthermore, the focus on developmental domains neglects the holistic development of the child. General comment No. 14 (OHCHR, 2013) states that Article 3 (best interests) involves ensuring "effective enjoyment of all the rights recognized in the Convention and the holistic development of the child" (p. 3). This includes physical, mental, spiritual, moral, psychological, and social development (OHCHR, 2013). The new OAP remains focused on ensuring children reach certain goals, using behavioural interventions, to develop along the Western developmental trajectory. Looking forward, it is important for the MCYS to define development and have it align with holistic development rather than development in only particular domains.

Medical model. The medical model continues to operate within the OAP. Children are a marginalized group (Mayall, 1998) and although they have rights, adults tend to treat them as 'incomplete humans' (Leibel, 2012). Autistic children are further marginalized because autism is pathologized (Glynne-Owen, 2010; Shyman, 2016) and viewed as a disease, leading adults to attempt to intervene (Broderick \& Ne'eman, 2008). The goal of behavioural services and 
supports is to normalize autistic children. The key areas in which the medical model arises are in the process of assessing and attempting to 'treat' autistic children.

Early studies on behavioural interventions relied on standardized assessments to measure changes in autistic children (for example see Lovaas et al., 1965; Lovaas et al., 1973; Lovaas, 1987). These methods continue to be used today and are evident in the OAP documents. The new OAP will no longer base eligibility on age or severity of autism (MCYS, 2017b). However, assessments will still be used to determine the type, duration, and intensity of intervention. The MCYS (2017b) suggests that age and severity of autism do not have an influence on the efficacy of intervention. Research on the efficacy of behavioural interventions paints a different picture. Research shows that children who are higher functioning and have a higher IQ prior to initiation of the intervention tend to perform better in the program (Ben Itzhak \& Zachor, 2007; Magiati et al., 2007; Perry et al., 2008; Rabinovich \& Lahat, 2007; Zachor \& Ben-Itzchak, 2010). There is a contradiction between what is presented in the OAP and what the research shows. It is important for the MCYS to assess whether it is in the best interests of all children to receive behavioural interventions when it is more efficacious for particular groups of autistic children.

The goal of behavioural interventions is to 'normalize' the child (Glynne-Owen, 2010; Shyman, 2016) and assessments provide a means for adults to make comparisons between children. Assessments are used to determine goals and outcomes for those participating in the program (MCYS, 2017a; MCYS, 2017b). They are serving to determine the deficits in the child and determine areas in which the child is not performing like their 'normal' peers. This method continues to perpetuate the binary of individuals with and without 'impairment' (Watson, 2012). The previous program presented the assessment information clearly and outlined how it would be used (MCYS, 2007; MCYS, 2011). The use of different assessments is mentioned in the 
documents but the only assessment named is the CANS (MCYS, 2017a; MCYS, 2017b).

Furthermore, the MCYS (2017a) state that more culturally responsive assessments will be used, but they do not provide examples of any assessments or strategies used to make assessments more culturally responsive.

Following the assessments, the services and supports are initiated. The behavioural clinician will use the data from the assessments to make 'treatment' decisions (MCYS, 2017a). Once the services and supports are in place, the behavioural clinician will also determine "treatment fidelity" (MCYS, 2017a, p. 22). These services and supports will be provided to gain "maximum therapeutic benefits" (MCYS, 2017b, p. 8). The way in which the goals of the intervention are discussed follows a medical model approach. The intervention process has the end goal of normalizing the autistic individual. Through a more social model of disability, the goal would be to make changes to the environment and society to make it more accessible for the autistic child (Oliver, 1996). By focusing on making changes to the child in order for them to fit in, autistic children are discriminated against based on their diagnosis. Based on Article 2 of the UNCRC (OHCHR, 1990), autistic children have the same rights as every other child. Attempts to change who they are, neglects to take this right into consideration. Furthermore, it prevents the child from their right to express themselves. In order to move away from the medical model in the OAP, supports and services should not be described as 'treatment' or 'therapeutic' because these terms perpetuate the idea that there is something wrong with the child.

The services and supports in the new OAP will address several domains of need (MCYS, 2017b). Many of these domains reflect the areas addressed in efficacy studies: communication, cognition, motor skills, adaptive skills, and social skills (MCYS, 2017b). However, the new OAP also explicitly lists play and leisure as one of the domains of need (MCYS, 2017b). The 
reasoning provided is that many autistic individuals lack "effective play and leisure skills" (MCYS, 2017b, p. 17). The inclusion of play and leisure in this list makes the statement that there is a 'right way' and 'wrong way' to participate in play and leisure. However, play is meant to be a pleasurable and spontaneous activity (Hirsh-Pasek \& Golinkoff, 2008). Something one child enjoys doing and considers play may differ from another child. By stating that there is an effective way to play, the child's choice of play is undermined. Furthermore, to have a childcentered approach, play should also be directed by the child. Shifting towards a social model, would lead to changes in the environment to facilitate children's play and leisure skills, while respecting Article 31 (the right to play and leisure) of the UNCRC (OHCHR, 1990). It would also provide them with opportunities to explore problems and questions of their choice (Kamii \& DeVries, 1993). It is important to not assess and measure children on every aspect of their daily lives. The domains of need perpetuate the idea that autistic children have deficits in these domains and adults should intervene to bring them to a level appropriate for their age and stage in development.

\section{Conclusion}

The new OAP is still in its early stages as the first phase of the program was implemented at the end of June 2017. The clinical framework (MCYS, 2017a) and the guidelines (MCYS, 2017b) provide a foundation for what the new program will look like. Although there has been a shift in the language used, the new policy documents continue to neglect children's rights. Both the clinical framework (MCYS, 2017a) and guidelines (MCYS, 2017b) provide an outline of the roles of different individuals through the various stages of service delivery. Children are not mentioned as active participants in any of the decision-making processes. Families and professionals are provided with the control and power in decision making in the documents, 
while youth are mentioned alongside these groups for some aspects of service delivery but not all. When these documents are translated into practice, children's rights will continue to be ignored because the professionals' role has not been described as including children in discussions and decision making. Instead children are treated as objects in the program, and decisions are made on their behalf.

Another implication of the new OAP is that Ontario will continue to provide solely behavioural interventions to autistic children and their families. The documents (MCYS, 2017a; MCYS, 2017b) only discuss the use of behavioural interventions and the program lacks the flexibility of including other options for children and their families. However, behavioural interventions may not be in the best interests of all children. As the efficacy studies demonstrate, behavioural interventions do not lead to the same results for all children. Autistic children are on a spectrum and there is variability between children, but the program has not adjusted for this variability by providing alternative options. Furthermore, the analysis of the new OAP supports the claim that autism is viewed as a disease (Broderick \& Ne'eman, 2008) and autistic individuals must be 'treated'. This notion perpetuates the idea of the binary between 'normal' and 'abnormal' (Shyman, 2016) and leads to attempts to change the child. The documents do not discuss supporting educators and other professionals to accommodate and make adjustments to support the child, but rather focus on changing aspects of the child to meet certain standards.

Overall, autistic children's voices and individuality continue to be put aside in favor of what adults believe children should be doing based on their age and stage in development. These ideologies of childhood, controlled by adults are present in all four documents. As the program is implemented across the province, it will be necessary to examine the program in practice to analyze how children's rights are respected or neglected by those working with them. 
The three themes that emerged from the findings are: power and dominance, ideologies of childhood, and the medical model. The findings provide evidence that the new OAP places autistic children at the bottom of a hierarchy which is controlled by adults, mainly the professionals who created and will implement the policy. Consequently, a children's rights framework continues to be left out of services and supports for autistic children. 


\section{Chapter 6: Concluding Comments}

\section{Introduction}

The first phase of the new OAP has been rolled out across Ontario. The OAP is still in its early stages, but an analysis of the policy documents demonstrates that children's rights are not being respected. Autistic children are not provided with a voice in the documents, and instead are described as passive recipients of services and supports. This section provides a conclusion to this study. I will provide recommendations for policy and practice, and highlight areas requiring further research. I will also present the significance of this study and an overview of the CDA conducted.

\section{Recommendations and Future Research}

This study established that a children's rights framework is missing from the documents outlining the new OAP. Although the MCYS has shifted towards a more family-centered approach, autistic children are still not active participants. I will outline the areas regarding recommendations for both policy and practice for the OAP to adopt a children's rights framework. I will also highlight the key areas regarding further research regarding autistic children's rights.

To incorporate a children's rights framework in the OAP, the MCYS must move away from an ages and stages, developmental model. A distinction between children and youth is made in the documents, but the MCYS (2017a; 2017b) does not define either group. The UNCRC (OHCHR, 1990) defines children as individuals under the age of 18. The MCYS should adopt the definition used in the UNCRC (OHCHR, 1990) and shift away from using age as the sole factor determining competency. This shift is also applicable to autistic children because of heterogeneity among autistics. Age alone cannot determine whether a child is competent and 
capable. Furthermore, I recommend that clinicians build a trusting relationship with the children they work with. Through this process, the clinician can gain a greater understanding of the stage the child is at and use this information to help determine the competency of the child.

One of the gaps in the OAP is the involvement of children in the assent/consent process. The current study echoes the claims made by Glynne-Owen (2010) and Ladd (2005) that assent is not sought from autistic children when they receive supports and services. In order to adopt a children's rights framework, clinicians should seek assent from the child participating in the intervention. The process may entail additional time and methods but it is essential that children be involved. The MCYS (2017a; 2017b) does not explicitly state throughout the documents that assent should be sought from children, but that does not mean that clinicians should neglect children's rights and neglect them in this process. Clinicians and families can use verbal and nonverbal cues, along with other aids such as visuals and augmentative and alternative communication devices to facilitate the process. Including children as active participants goes beyond the assent process. It is important to acknowledge that youth's voices are provided with more weight in the new OAP documents. There is a shift to viewing youth as experts and this is an important change. Clinicians must carry this out in practice to respect their rights. However, autistic children should not be discriminated against because of others' perceptions about their abilities. Professionals working with autistic children have an obligation to treat every child as their own person, and not rely on age and beliefs about the child's abilities when making decisions about their participation.

The OAP remains limited in the scope of supports and services provided to children and their family. Only behavioural supports and services are available for autistic children and their families through the MCYS. They have not tried to make changes in this area. The one size fits 
all approach fails to account for the individuality and diversity of autistic children and their families. In fact, one size does not fit all, and each child must be treated as an individual. The goal of behavioural interventions is to modify children to fit into society and the system in place (Glynne-Owen, 2010). The MCYS continues to use this medical model approach in its delivery of services and supports for autistic children and youth. If the MCYS were to respect the rights of children, the medical model approach to intervention would not be used. To make this change, the focus must be on providing education and support for those who work directly with autistic children. Changes are needed at the level of institutions such as schools, to effectively support autistic children without the goal of attempting to change who they are.

Research regarding behavioural interventions for autistic children has been focused on quantitative, efficacy studies. The goal of these studies is to determine the changes in children by conducting standardized assessments before and after the intervention. This quantitative data is not supplemented with qualitative information about the process and the participants' experiences and feelings. For children to be active participants, a change in how research on interventions is carried out is needed. Research continues to be 'done on' autistic children, but a shift is needed to conduct research 'with' autistic children. This is also where the assent process should begin. Research on behavioural interventions do not outline whether assent was sought from the child participating in the research (Glynne-Owen, 2010; Ladd, 2005). A precedent is set by this research and carries out throughout the delivery of services and supports for autistic children. If children's rights are incorporated during the research process, there would be more accountability to incorporate it within the autism programs themselves.

The shift to working 'with' children, rather than 'on' children also requires a change in the use of assessments to measure and compare children. Quantitative approaches using 
standardized assessments fail to account for children's differences. There is more to children than how they score compared to a 'normal' child of the same age. The use of assessments to determine a child's abilities neglects looking at the child in a holistic manner. Children's development and well-being encompasses a wide range of areas but assessments do not allow for the measurement of each area. Furthermore, although the new OAP states that assessments will be culturally responsive, it fails to acknowledge that the developmental model used within the OAP is based on Westernized ideals of development. Individuals from different social groups and cultures may not identify with this model. To be culturally responsive, the MCYS actually must work with individuals and groups from different cultures and social groups to incorporate their beliefs and values in service delivery.

For the purposes of this study, I did not analyze the use of waitlists in intervention services available to autistic children. From my discussions with professionals in the field, the average wait time for a diagnosis and to access services and supports is $12-18$ months. Gordon (2012) reported that wait times for services for autistic children across Ontario, ranged from 10 months to 4 years, depending on the region the family and child resided in. This is a violation of children's right to optimal health care (Article 24) (OHCHR, 1990). Autistic children and their families are not receiving support and services in a timely manner. This is a systemic issue that must be dealt with regarding all early childhood education and care services. The MCYS (2017a; 2017b) does not outline how they will support children and families on waitlists. A more coordinated approach and increased funding is required to decrease wait times for early year services. Further studies are required to examine the problem of waitlists from a systemic perspective and the impact it has on the children and families. 


\section{Significance}

This study is significant because it provides what is probably the first analysis of the newly released OAP, which was introduced during the course of this study. The MCYS has been releasing information about this new program for the past 18 months and had promised a new and changed program for autistic children and their families. This study is also significant because it provides an analysis through a children's rights framework supplemented by CDS and the sociology of childhood. The intersectionality of childhood and disability is important to examine especially with respect to disabled children's rights. Based on a thorough search of the literature on autism intervention policies and programs, it became clear that there is a gap in research examining autistic children's rights. The study presented here contributes significantly to the limited research available on the topic. The study also provides a foundation for conducting not only an analysis of the program in practice but also on the use of behavioural interventions for autistic children using a more qualitative, participatory method. Going forward, autistic children and adults should have an active role in the research directly impacting their daily lives. As the OAP is rolled out across the province, this study could support the need for change with respect to the role of autistic children in the policy.

\section{Conclusion}

The purpose of this CDA was examine the role of autistic children's rights in the new OAP policy documents. A CDA informed by van Dijk (1993; 1995) and Fairclough (1995) was conducted on the clinical framework (MCYS, 2017a) and guidelines (MCYS, 2017b) for the new program in addition to the documents from the previous program (MCYS, 2007; MCYS, 2011). A children's rights framework supplemented by CDS and the sociology of childhood guided the analysis of the documents. 
Following an analysis of the findings, three key themes emerged from the documents. The ideas of power and dominance were prominent in the OAP. Adults such as professionals hold the power, as outlined by their role in the documents, and children are at the bottom of the hierarchy in terms of participation. The ideologies of childhood present in the OAP depict autistic children as dependent on adults in their lives. The medical model provides the foundation for the OAP. The focus of the documents remains on 'treating' and changing autistic children. Although the new OAP has made changes in some areas regarding how services and supports will be provided to children, youth, and their families, it still lacks a children's rights framework. From the creation of the new OAP, to the assent process, and decision making, children are passive objects. They are silenced and 'treated' to fit the Westernized norm of childhood. The first phase of the new program has begun, but going forward the MCYS needs to consider the rights of children and their role in the OAP from beginning to end. This change must begin with a shift in how research is conducted with autistic children and the interventions they participate in. By incorporating a more qualitative, participatory approach at this stage, autistic children's voices and experiences can be brought to the forefront, and their rights can be respected. 


\section{References}

American Psychiatric Association. (2013). Diagnostic and statistical manual of mental disorders (5th ed.). Washington, DC: American Psychiatric Association.

Autism Ontario. (2017). Autism Ontario knowledge base. Retrieved from http://autismontario.novosolutions.net/default.asp

Ben-Itzchak, E., \& Zachor, D. A. (2007). The effects of intellectual functioning and autism severity on outcome of early behavioral intervention for children with autism. Research in Developmental Disabilities, 28(3), 287-303.

Binet, A., \& Simon, T. (1948). The development of the Binet-Simon scale, 1905-1908. In W. Dennis (Ed.), Readings in the history of psychology (pp. 412-424). New York, NY: Appleton-Century-Crofts.

Breeze, R. (2011). Critical discourse analysis and its critics. International Pragmatics Association, 21(4), 493-525.

Broderick, A. A., \& Ne'eman, A. (2008). Autism as a metaphor: Narrative and counter-narrative. International Journal of Inclusive Education, 12(5-6), 459-576.

Chance, P. (1974, January). Poet with a cattle prod. Psychology Today. Retrieved from http://neurodiversity.com/library_chance_1974.pdf

Chouliaraki, L., \& Fairclough, N. (1999). Discourse in late modernity: Rethinking critical discourse analysis. Edinburgh, UK: Edinburgh University Press.

Cohen, H., Amerine-Dickens, M. S., \& Smith, T. (2006). Early intensive behavioral treatment: Replication of the UCLA model in a community setting. Journal of Developmental and Behavioral Pediatrics, 27(2), 145-155. 
Creswell, J. W. (2014). Research design: Qualitative, quantitative, and mixed methods approaches (4th ed.). Thousand Oaks, CA: Sage Publications Inc.

Eikeseth, S., Smith, T., Jahr, E., \& Eldevik, S. (2007). Outcome for children with autism who began intensive behavioral treatment between ages 4 and 7: A comparison controlled study. Behavior Modification, 31(3), 264-278.

Eikeseth, S., Klintwall, L., Jahr, E., \& Karlsson, P. (2012). Outcome for children with autism receiving early and intensive behavioral intervention in mainstream preschool and kindergarten settings. Research in Autism Spectrum Disorders, 6(2), 829-835.

Elwood, J., \& Lundy, L. (2010). Revisioning assessment through a children's rights approach: Implications for policy, process and practice. Research Papers in Education, 25(3), 335353.

Fairclough, N. (1995). Critical discourse analysis: The critical study of language. New York, NY: Longman Publishing.

Fairclough, N. (2003). Analyzing discourse: Textual analysis for social research. London, UK: Routledge.

Foucault, M. (1980). Power/knowledge: Selected interviews and other writings, 1972-1977. C. Gordon (Ed.). New York, NY: Pantheon.

Freeman, N., \& Perry, A. (2010). Outcomes of intensive behavioural intervention in the Toronto preschool autism service. Journal on Developmental Disabilities, 16(2), 17-32.

Gee, J. P. (2014). How to do discourse analysis: A toolkit. New York, NY: Routledge.

Glynne-Owen, R. (2010). Early intervention and autism: The impact of positivism and the call for change. International Journal of Children's Rights, 18(3), 405-416. 
Gordon, A. (2012, November 23). The autism project: Wait times. The Toronto Star. Retrieved from https://www.thestar.com/news/gta/2012/11/23/the_autism_project_wait_times.html

Gordon, A. (2016a, April 1). Families 'devastated' by changes to Ontario autism program. The Toronto Star. Retrieved from https://www.thestar.com/life/2016/04/01/familiesdevastated-by-changes-to-ontario-autism-program.html

Gordon, A. (2016b, June 28). Ontario backs off controversial autism changes, boosts services after parents protest. The Toronto Star. Retrieved from https://www.thestar.com/news/queenspark/2016/06/28/ontario-pours-200-million-moreinto-autism-care-in-response-to-parents-anger.html

Granpeesheh, D., Dixon, D. R., Tarbox, J., Kaplan, A. M., \& Wilke, A. E. (2009). The effects of age and treatment intensity on behavioral intervention outcomes for children with autism spectrum disorders. Research in Autism Spectrum Disorders, 3(4), 1014-1022.

Hayward, D., Eikeseth, S., Gale, C., \& Morgan, S. (2009). Assessing progress during treatment for young children with autism receiving intensive behavioural interventions. Autism, 13(6), 613-633.

Hirsh-Pasek, K., and Golinkoff, R. (2008). Why play = learning. Encyclopedia on Early Childhood Development. Retrieved from http://www.childencyclopedia.com/play/according-experts/why-play-learning

James, A., \& Prout, A. (1997). Constructing and reconstructing childhood: Contemporary issues in the sociological study of childhood. London, UK: Falmer Press.

Kamii, C., \& DeVries, R. (1993). Physical knowledge in preschool education: Implications of Piaget's theory. New York, NY: Teacher's College Press. 
Ladd, R. E. (2005). Rights of the autistic child. The International Journal of Children's Rights, $13(1-2), 87-98$.

Laws, K. R. (2013). Negativland - a home for all findings in psychology. BMC Psychology, 1(1) $1-8$

Laws, K. R. (2016a). Commentary: Does cognitive behavior therapy for psychosis (CBTp) show a sustainable effect on delusions? A meta-analysis. Frontiers in Psychology, 7, 59.

Laws, K. R. (2016b). Psychology, replication \& beyond. BMC Psychology, 4(1), 30.

Liebel, M. (2012). Children's rights from below: Cross-cultural perspectives. Basingstoke, UK: Macmillan Education.

Lord, C., Rutter, M., DiLavore, P. C., \& Risi, S. (1999). Autism diagnostic observation scheduleWPS (ADOS-WPS). Los Angeles, CA: Western Psychological Services.

Lovaas, O.I., Schaffer, B., \& Simmons, J. Q. (1965). Building social behavior in autistic children by use of electric shock. Journal of Experimental Research in Personality, 1, 99-109.

Lovaas, O. I., Koegel, R., Simmons, J. Q., \& Long, J. S. (1973). Some generalization and follow up measures on autistic children in behavior therapy. Journal of Applied Behavior Analysis, 6(1), 131-166.

Lovaas, O. I. (1987). Behavioral treatment and normal educational and intellectual functioning in young autistic children. Journal of Consulting and Clinical Psychology, 55(1), 3-9.

Lundy, L. (2007). 'Voice' is not enough: Conceptualising Article 12 of the United Nations Convention on the Rights of the Child. British Educational Research Journal, 33(6), $927-942$. 
Magiati, I., Charman, T., \& Howlin, P. (2007). A two-year prospective follow-up study of community-based early intensive behavioural intervention and specialist nursery provision for children with autism spectrum disorders. Journal of Child Psychology and Psychiatry, 48(8), 803-812.

Mayall, B., (1998). Towards a sociology of child health. Sociology of Health and Illness, 20(3), 269-288.

Mayall, B. (2000). The sociology of childhood in relation to children's rights. The International Journal of Children's Rights, 8(3), 243-259.

Ministry of Children and Youth Services. (2007). Autism intervention program-program guidelines. Retrieved from http://www.children.gov.on.ca/htdocs/English/professionals/specialneeds/aip_guidelines. aspx

Ministry of Children and Youth Services. (2011). Guidelines, applied behaviour analysis-based services and supports for children and youth with ASD. Retrieved from http://www.children.gov.on.ca/htdocs/English/professionals/specialneeds/guidelines/guid elines-2011.aspx

Ministry of Children and Youth Services. (2017a). Ontario autism program clinical framework. Retrieved from http://www.children.gov.on.ca/htdocs/English/documents/specialneeds/autism/OAPClini calFrameworkEN.pdf

Ministry of Children and Youth Services. (2017b). Ontario autism program guidelines. Retrieved from 
http://www.children.gov.on.ca/htdocs/English/documents/specialneeds/autism/OAPGuid elinesEN.pdf

Ministry of Children and Youth Services. (2017c). Ontario transforming autism services for children and their families. Retrieved from https://news.ontario.ca/mcys/en/2017/06/ontario-transforming-autism-services-forchildren-and-their-families.html

Mohammadzaheri, F., Koegel, L. K., Rezaee, M., \& Rafiee, S. M. (2014). A randomized clinical trial comparison between pivotal response treatment (PRT) and structured applied behavior analysis (ABA) intervention for children with autism. Journal of Autism and Developmental Disorders, 44(11), 2769-2777.

National Research Council. (2001). Educating children with autism. Washington, DC: National Academies Press.

O’Connor, A. B., \& Healy, O. (2010). Long-term post-intensive behavioral intervention outcomes for five children with autism spectrum disorder. Research in Autism Spectrum Disorders, 4(4), 594-604.

Office of the High Commissioner for Human Rights. (1990). Convention on the Rights of the Child. Retrieved from http://www.ohchr.org/EN/ProfessionalInterest/Pages/CRC.aspx Office of the High Commissioner for Human Rights. (2008). Convention on the Rights of Persons with Disabilities. Retrieved from http://www.un.org/disabilities/documents/convention/convoptprot-e.pdf Office of the High Commissioner for Human Rights. (2005). Convention on the Rights of the Child: General comment No. 7: Implementing child rights in early childhood. Geneva, Switzerland: United Nations. 
Office of the High Commissioner for Human Rights. (2013). Convention on the Rights of the Child: General comment No. 14: On the right of the child to have his or her best interests taken as a primary consideration. Geneva, Switzerland: United Nations.

Oliver, M. (1996). Understanding disability: from theory to practice. Basingstoke, UK: Macmillan Education.

Pierce, K., \& Schreibman, L. (1995). Increasing complex social behaviors in children with autism: Effects of peer-implemented pivotal response training. Journal of Applied Behavior Analysis, 28(3), 285-295.

Perry, A., Cummings, A., Dunn Geier, J., Freeman, N. L., Hughes, S., LaRose, L., . . Williams, J. (2008). Effectiveness of intensive behavioral intervention in a large, community-based program. Research in Autism Spectrum Disorders, 2(4), 621-642.

Remington, B., Hastings, R. P., Kovshoff, H., Espinosa, F., Jahr, E., Brown, T., ... Ward, N. (2007). Early intensive behavioral intervention: Outcomes for children with autism and their parents after two years. American Journal on Mental Retardation, 112(6), 418-438.

Rosenbaum, P., King, S., Law, M., King, G., Evans, J. (1998). Family-centred service. Physical \& Occupational Therapy in Pediatrics, 18(1), 1-20.

Sambandam, E., Rangaswami, K., \& Thamizharasan, S. (2014). Efficacy of ABA programme for children with autism to improve general development, language and adaptive behaviour. Indian Journal of Positive Psychology, 5(2), 192-195.

Schopler, E., Reichler, R. J., \& Renner, B. R. (1988). The childhood autism rating scale (CARS). Los Angeles, CA: Western Psychological Services. 
Shyman, E. (2016). The reinforcement of ableism: Normality, the medical model of disability, and humanism in applied behavior analysis and ASD. Intellectual and Developmental Disabilities, 54(5), 366-376.

Skinner, B. F. (1974). About behaviorism. Toronto, ON: Random House of Canada Limited. Skinner, B. F. (2014). A world of our own. European Journal of Behavior Analysis, 15(1), 2124. (Reprinted from Behaviorology, 1, 1993, pp. 1-5).

Smits, T., Lakens, D. D., Ritchie, S., \& Laws, K. (2014). Statistical errors and omissions in a trial of cognitive behavior techniques for psychosis: Commentary on Turkington et al. Journal of Nervous and Mental Disease, 202(7), 566.

Sparrow, S., Balla, D. A., \& Cicchetti, D. (1984). Vineland adaptive behavior scales. Circle Pines, MN: American Guidance Service.

van Dijk, T. A. (1993). Principles of critical discourse analysis. Discourse \& Society, 4(2), 249283.

van Dijk, T. A. (1995). Aims of critical discourse analysis. Japanese Discourse, 1(1), 17-27. Watson, N. (2012). Theorising the lives of disabled children: How can disability theory help? Children \& Society, 26(2), 192-202.

Welterlin, A., \& LaRue, R. H. (2007). Serving the needs of immigrant families of children with autism. Disability \& Society, 22(7), 747-760.

Zachor, D. A., Ben-Itzchak, E., Rabinovich, A., \& Lahat, E. (2007). Change in autism core symptoms with intervention. Research in Autism Spectrum Disorders, 1(4), 304-317.

Zachor, D. A., \& Ben-Itzchak, E. (2010). Treatment approach, autism severity and intervention outcomes in young children. Research in Autism Spectrum Disorders, 4(3), 425-432. 